\title{
Exo-erythrocytic development of avian malaria and related haemosporidian parasites
}

\author{
Gediminas Valkiūnas* and Tatjana A. lezhova
}

\begin{abstract}
Background: Avian malaria parasites (Plasmodium spp.) and related haemosporidians (Haemosporida) are responsible for diseases which can be severe and even lethal in avian hosts. These parasites cause not only blood pathology, but also damage various organs due to extensive exo-erythrocytic development all over the body, which is not the case during Plasmodium infections in mammals. However, exo-erythrocytic development (tissue merogony or schizogony) remains the most poorly investigated part of life cycle in all groups of wild life haemosporidian parasites. In spite of remarkable progress in studies of genetic diversity, ecology and evolutionary biology of avian haemosporidians during the past 20 years, there is not much progress in understanding patterns of exo-erythrocytic development in these parasites. The purpose of this review is to overview the main information on exo-erythrocytic development of avian Plasmodium species and related haemosporidian parasites as a baseline for assisting academic and veterinary medicine researchers in morphological identification of these parasites using tissue stages, and to define future research priorities in this field of avian malariology.
\end{abstract}

Methods: The data were considered from peer-reviewed articles and histological material that was accessed in zoological collections in museums of Australia, Europe and the USA. Articles describing tissue stages of avian haemosporidians were included from 1908 to the present. Histological preparations of various organs infected with the exo-erythrocytic stages of different haemosporidian parasites were examined.

Results: In all, 229 published articles were included in this review. Exo-erythrocytic stages of avian Plasmodium, Fallisia, Haemoproteus, Leucocytozoon, and Akiba species were analysed, compared and illustrated. Morphological characters of tissue stages that can be used for diagnostic purposes were specified.

Conclusion: Recent molecular studies combined with histological research show that avian haemosporidians are more virulent than formerly believed. The exo-erythrocytic stages can cause severe disease, especially in non-adapted avian hosts, suggesting the existence of a group of underestimated malignant infections. The development of a given haemosporidian strain can be markedly different in different avian hosts, resulting in significantly different virulence. A methodology combining the traditional histology techniques with molecular diagnostic tools is essential to speed research in this field of avian malariology.

Keywords: Avian malaria, Plasmodium, Fallisia, Haemoproteus, Leucocytozoon, Akiba, Exo-erythrocytic development, Pathology

\section{Background}

Malaria parasites (species of Plasmodium) and related haemosporidians of the order Haemosporida are widespread and diverse pathogens infect many species of the major groups of vertebrates, which are exposed to bites

*Correspondence: gedvalk@ekoi.lt

Nature Research Centre, Akademijos 2, LT-08412 Vilnius, Lithuania of blood-sucking dipteran insects (Diptera). The latter insects are specific vectors of haemosporidians [1]. Many species of reptiles, birds and mammals are often parasitized, and several species of amphibians and even fish have been reported as hosts of haemosporidians [2-6]. The life cycle of these blood parasites includes the following main obligatory stages: (1) exo-erythrocytic merogony (schizogony); (2) development in blood cells and 
production of gametocytes, which are infective for vectors; and, (3) sexual process and sporogony occurring in dipteran insects, which inject infective sporozoites and initiate new infections in vertebrate hosts. General descriptions of life cycles of different malaria and related haemosporidian species are available in several books and reviews [2-9]. However, the details of development of these pathogens both in avian hosts and vectors remain unknown for the great majority of the described species. This study reviews knowledge and provides comparative morphological data about exo-erythrocytic development of avian malaria and related haemosporidian parasites of the families Plasmodiidae, Haemoproteidae, Garniidae, and Leucocytozoidae.

Avian malaria parasites and other haemosporidians cause not only blood pathology due to development of high parasitaemia, but also pathology in organs because of the damage caused by exo-erythrocytic stages, which often develop in various non-specialized reticuloendothelial cells and can be found all over the body in susceptible birds, including the brain, eyes, nerves, heart, skeletal muscles, and many others organs and tissues $[2-7,10]$. From this point of view, avian malaria caused by some Plasmodium species is an even more severe disease than mammalian malaria, during which the exoerythrocytic development occurs mainly in hepatic cells and usually does not cause disease at this stage of infection $[11,12]$.

During the last 20 years, numerous studies have addressed the taxonomy, genetic diversity, ecology, evolutionary biology, and genetics of avian haemosporidians (reviewed in [13-19]). The application of sensitive polymerase chain reaction (PCR)-based diagnostic methods, using relatively easy-to-collect samples of infected peripheral blood, provided much new knowledge about these topics, but contributed little information about exoerythrocytic development. The great majority of recent avian haemosporidian studies only used blood samples to assess haemosporidian infections, which gives no information on the tissue stages. It is important to note that several recent histopathological studies, which combined molecular diagnostic and microscopic research, showed that widespread haemosporidian lineages, particularly of Haemoproteus species, may cause severe disease and even mortality in birds due to marked damage by exoerythrocytic meronts [20-26]. Interestingly, abortive development of tissue stages of haemosporidians in nonadapted avian hosts caused mortality, and that is a new issue related to bird health in studies of exo-erythrocytic development of avian haemosporidians.

Abortive development happens when a parasite invades a 'wrong' host, succeeds to develop partially, but cannot complete its full life cycle, resulting in the absence of invasive stages (gametocytes in avian hosts or sporozoites in vectors). The parasite is 'captured' by the host during abortive development, which is a dead-end of the infection [27-29]. Infections in 'wrong' hosts are usually eliminated rapidly, with minimal or no symptoms, as was reported in non-successful experimental infections $[4,5]$. However, if the infection proceeds partially, the immune response to get rid of it may be highly symptomatic. Abortive haemosporidian infections usually are difficult to diagnose because of unusual location and morphology in the 'wrong' host, unclear etiology, short-term survival of parasites or rapid mortality of infected hosts [22, 28-30].

In old literature (published before 1995), there are numerous descriptions of lethal avian diseases of unclear etiology caused by tissue stages of haemosporidians [3143]. The tissue stages in dead birds sometimes resemble the megalomeronts of Leucocytozoon species, which is why these diseases were formerly often described as 'aberrant Leucocytozoon infections' or even 'Besnoitia infections' [44]. Recent molecular studies and histopathological research indicate that widespread lineages of haemosporidians are responsible for mortality due to the damage caused by tissue stages of these parasites [20-26, 45]. The application of molecular diagnostic tools indicates that haemosporidian infections might kill abnormal vertebrate hosts during exo-erythrocytic development [22, 29]. For example, the prevalence of Haemoproteus minutus (Haemoproteidae) infection is high $(>50 \%)$ in most blackbird Turdus merula populations in Europe, and active transmission takes place even in parks of European capitals [26]. The blackbird is adapted to this infection, which is asymptomatic in this host, but $H$. minutus cause lethal disease in captive parakeets in Europe. Abortive tissue stages of this parasite develop in myocardial and skeletal muscles and other organs, but parasitaemia is absent, making it difficult to diagnose such infections by microscopic examination or PCR-based testing solely of blood samples [22, 23]. Presence of haemosporidians can be reported in organs of birds using solely molecular diagnostic tools [46], but this methodology is insufficiently sensitive to understand pathology caused by the parasites. Traditional histological methods remain important in morphological characterization of haemosporidian tissue stages [47]. However, the descriptions and illustrations of these stages are scattered throughout numerous publications, many of which are old, not easy to access and sometimes are difficult to use for comparative parasitology research.

The aims of this review were: (1) to overview main available information on exo-erythrocytic development of avian Plasmodium and related haemosporidian parasites; and, (2) to discuss future research priorities in this 
field of avian malariology. This study provides images of common haemosporidian exo-erythrocytic stages, which can be used during identification of these infections. Information about pathological changes in bird organs is only briefly mentioned; it is available in several reviews $[2-5,48]$ and its detailed consideration requires separate analysis.

\section{Methods}

\section{Collection of literature}

Mainly, full-length papers published in peer-reviewed journals were considered. Old articles (published before 1995) were collected by the first author during his work in the libraries of Oxford University, Natural History Museum, the Liverpool School of Tropical Medicine, and the International Centre for Avian Haematozoa (now available in the Queensland Museum, Australia) in 1992-1996. Published bibliographies of the avian blood-inhabiting haematozoa [49-51] and reviews on haemosporidian parasites $[2-5,7-9,52,53]$ were also used. Recent peer-reviewed articles have been retrieved from online bibliographic databases PubMed, SCOPUS and Google Scholar using the following keywords: 'malaria, 'birds', 'Haemoproteus', 'Plasmodium,' 'Leucocytozoon, 'Akiba, 'Fallisia', 'pathology', 'meront,' 'schizont'. The Boolean operators 'OR', 'AND', and ' '> were used to combine several terms. In all, 229 full text articles and short reports were reviewed. Articles are cited in the review if they explicitly provided data about one of the considered aspects of exo-erythrocytic development or genetic diversity of avian malaria or other haemosporidian parasites; 212 papers containing most representative information about exo-erythrocytic development of these parasites are incorporated in the References.

\section{Collection material and microscopic examination}

Histological preparations of exo-erythrocytic stages were obtained from the collections of International Reference Centre for Avian Haematozoa (Queensland Museum, Queensland, Australia), Natural History Museum (London, UK), Nature Research Centre (Vilnius, Lithuania) and the US National Parasite Collection (National Museum of Natural History, Washington DC, USA). All accessed preparations were studied. An Olympus BX61 light microscope (Olympus, Tokyo, Japan) equipped with an Olympus DP70 digital camera and imaging software AnalySIS FIVE (Olympus Soft Imaging Solution GmbH, Münster, Germany) was used to examine preparations and prepare illustrations.

\section{Results}

Exo-erythrocytic development of avian malaria parasites

Information about exo-erythrocytic development of avian malaria parasites of the genus Plasmodium comes mainly from studies carried out by human malaria researchers who used these bird parasites, mainly of subgenera Haemamoeba and Giovannolaia as models for better understanding of human disease between the 1930s and 60s (reviews in [2-5, 7-9, 52, 54, 55]. Raffaele [56] provided first data about exo-erythrocytic development in birds experimentally infected with Plasmodium elongatum. The discovery and excellent illustrations of exo-erythrocytic meronts of Plasmodium gallinaceum in brain capillaries and other tissues of domestic chickens by James and Tate $[57,58]$ was the first real evidence of tissue stages in malaria parasites. These studies markedly stimulated the development of avian malariology and also activated the search of tissue stages in Plasmodium parasites of mammals. Exo-erythrocytic development of several Haemamoeba and Giovannolaia malaria parasites were subjects of experimental research in many laboratories in America and Europe (Table 1). However, after the discovery of malaria parasites in rodents and monkeys, which are closer to malaria parasites of humans in many biological and genetic characteristics and also are more convenient model organisms for the laboratory experimental research, the interest of human malariologists in avian malaria parasites gradually decreased in the $1960 \mathrm{~s}$ $[3,4,9,53]$. Because of the difficulties in designing experiments with parasites of wild birds and the unidentified vectors of many Plasmodium species, the exo-erythrocytic development of the great majority of avian malaria parasites of subgenera Giovannolaia, Novyella and Huffia remains unknown or only fragmentary information about their secondary exo-erythrocytic merogony is available (Table 1).

The complete exo-erythrocytic development is known only for three species of subgenus Haemamoeba, and three species of subgenus Giovannolaia (Table 1). The tissue stages and the sequence of their development have been relatively well studied in Plasmodium cathemerium, Plasmodium fallax, P. gallinaceum, Plasmodium garnhami, Plasmodium lophurae, and Plasmodium relictum. Experiments with these parasites were relatively easy to design because their vectors (mosquitoes of the genera Culex, Aedes and some others) have been identified and colonized. Additionally, susceptible avian hosts (chickens, ducklings, turkeys, domestic pigeons, and canaries) of these parasites are easy to maintain in the laboratory [2, $4,5,52-55,58,61,73,74,93,125]$. In these parasites, the general pattern of exo-erythrocytic development is similar, and it is likely to be similar in other species of these subgenera. Mainly, sporozoites induce exo-erythrocytic development in the cells of mesodermal origin, particularly often in the cells of lymphoid-macrophage system and the endothelial cells lining capillaries. Erythrocytic meronts and gametocytes develop in red blood cells. 
Table 1 Exoerythrocytic stages reported in different avian Plasmodium parasites

\begin{tabular}{|c|c|c|c|c|}
\hline \multirow[t]{2}{*}{ Subgenus and species } & \multicolumn{3}{|l|}{ Stage } & \multirow[t]{2}{*}{ Reference } \\
\hline & Cryptozoite & Metacryptozoite & Phanerozoite & \\
\hline \multicolumn{5}{|l|}{ Haemamoeba } \\
\hline Plasmodium cathemerium & + & + & + & {$[54,59,60]$} \\
\hline P.gallinaceum & + & + & + & {$[7,8,10,54,55,57,58,61-63]$} \\
\hline P. giovannolai & $-{ }^{\mathrm{a}}$ & - & + & {$[64,65]$} \\
\hline P. subpraecox & - & - & + & {$[66]$} \\
\hline P.lutzi & - & - & + & {$[67]$} \\
\hline P. matutinum & - & - & + & {$[2,68-72]$} \\
\hline P. relictum & + & + & + & {$[8,54,73-76]$} \\
\hline P. tejerai & - & - & + & {$[60,77-79]$} \\
\hline \multicolumn{5}{|l|}{ Giovannolaia } \\
\hline P. circumflexum & - & - & + & [80-84] \\
\hline P. durae & - & - & + & {$[53,85-89]$} \\
\hline P. fallax & + & + & + & {$[55,90,91]$} \\
\hline P. gabaldoni & & & + & {$[92]$} \\
\hline P.garnhami & + & + & + & {$[2,93]$} \\
\hline P. homocircumflexum & - & - & + & {$[94]$} \\
\hline P. lophurae & + & + & + & {$[2,55,95-97]$} \\
\hline P. octamerium & - & - & + & {$[98]$} \\
\hline P. pinottii & - & - & + & {$[2,99]$} \\
\hline P.polare & - & + & - & {$[2,100-103]$} \\
\hline \multicolumn{5}{|l|}{ Novyella } \\
\hline P. bertii & - & - & - & [104] \\
\hline P. dissanaikei & - & - & + & [105] \\
\hline P. hexamerium & - & - & + & {$[106]$} \\
\hline P. nucleophilum & - & - & + & {$[60,107,108]$} \\
\hline P. paranucleophilum & - & - & + & [109] \\
\hline P. vaughani & - & + & + & {$[2,110,111]$} \\
\hline \multicolumn{5}{|l|}{ Bennettinia } \\
\hline P. juxtanucleare & - & - & + & {$[2,112-114]$} \\
\hline \multicolumn{5}{|l|}{ Huffia } \\
\hline P. elongatum & - & - & + & {$[2,55,115-118]$} \\
\hline P. hermani & - & - & + & [119-122] \\
\hline P. huffi & - & - & + & {$[2,123,124]$} \\
\hline
\end{tabular}

Only parasites, which species identification was supported by morphological or molecular identifications were included in this table. Reports of unidentified parasites or the parasites of undetermined or questionable taxonomic status were not included. To date, approximately 50 avian Plasmodium species were described, and 738 lineages of these parasites were reported (according to MalAvi database, http://mbio-serv2.mbioekol.lu.se/Malavi)

a Exoerythrocytic stages were not seen

The exo-erythrocytic merogony can be arbitrarily classified in two main stages: the primary (pre-erythrocytic) merogony, which occurs before parasitaemia, and the secondary (post-erythrocytic) merogony, which develops during parasitaemia and maintains at the latency stage. The primary exo-erythrocytic merogony consists at least of two generations of meronts, which are named the cryptozoites and metacryptozoites, respectively. The secondary exo-erythrocytic merogony includes several generations of meronts named the phanerozoites. It is important to note that the development of phanerozoites can be induced by merozoites developed in the erythrocytic meronts, which is not the case in malaria parasites of mammals $[2,4,5,11]$.

Mosquitoes inject sporozoites in birds and initiate development of the first generation of primary exo-erythrocytic meronts (cryptozoites), which develop in the reticular cells of many organs and tissues, including the skin (Fig. 1a-c) [54, 55, 73, 91]. The localization of cryptozoites in bird body depends on the mode of infection. 


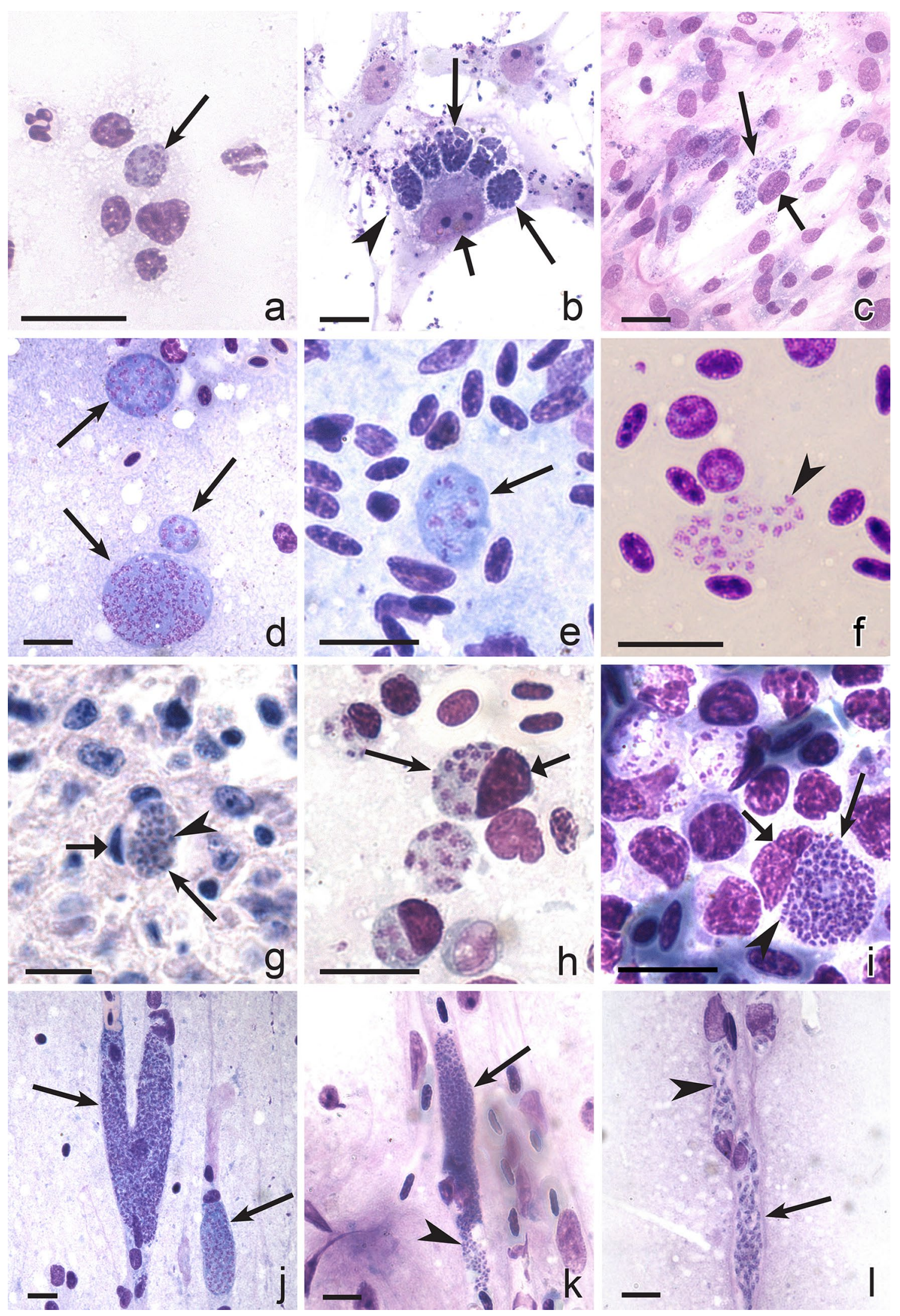


(See figure on previous page.)

Fig. 1 Exo-erythrocytic stages of avian malaria parasites: cryptozoites (a-c), metacryptozoites $(\mathbf{d})$ and phanerozoites (e-I). Plasmodium cathemerium in wing skin of a domestic canary Serinus canaria approximately 2.5 days after inoculation of sporozoites (note small size of maturing cryptozoite, a). Plasmodium fallax in culture of brain cells from a turkey Meleagris gallopavo embryo (note five mature cryptozoic meronts and numerous mature dispersed merozoites, b). Plasmodium lophurae in culture of brain cells from a turkey embryo (note numerous small mature cryptozoic meronts located in groups, c). Plasmodium garnhami in histological section of liver of the hoopoe Upupa epops experimentally infected by sporozoites (note the plentiful basophilic cytoplasm and prominent different size nuclei in three metacryptozoic meronts in different stages of growth, $\mathbf{d}$ ). Growing phanerozoic meront of Plasmodium gabaldoni in the spleen of the pigeon Columba livia infected by inoculation of infected blood (note the plentiful basophilic cytoplasm and prominent nuclei, e). Mature merozoites of Plasmodium gabaldoni in a brain smear of turkey experimentally infected by inoculation of infected blood (note prominent irregular shape nuclei in mature merozoites, $\mathbf{f}$ ). Mature phanerozoic meront of Plasmodium durae in spleen of turkey experimentally infected by inoculation of infected blood (note small size of the mature meront and a deformed host cell nucleus, $\mathbf{g}$ ). Plasmodium elongatum in a smear of bone marrow of a European greenfinch Carduelis chloris infected by inoculation of infected blood (note three intracellular parasites in different stages of growth in stem cells and one extracellular meront, $\mathbf{h}$ ). Plasmodium huffi in a smear of bone marrow of a toco toucan Ramphastos toco experimentally infected by inoculation of infected blood (note one mature meront and several growing meronts, which markedly displace and deform host cell nuclei, i). Elongate phanerozoic meronts of Plasmodium gallinaceum blocking cerebral capillaries (note two meronts in different stages of growth, $\mathbf{j}$ ). Mature phanerozoic meronts of Plasmodium pinottii in a brain smear of experimentally infected domestic pigeon Columba livia ( $\mathbf{k}, \mathbf{l})$ : note numerous roundish merozoites (micromerozoites, $\mathbf{k}$ ) and elongate merozoites (macromerozoites, I) in cerebral capillaries. Simple long arrows meronts, triangle wide shot arrows host cell nuclei, simple arrowheads merozoites. Scale bars $10 \mu \mathrm{m}$

After inoculation of sporozoites into skin, the cryptozoites often develop initially in macrophages or fibroblasts (Fig. 1a), sometimes in lymphocytes and fat cells, located close to the site of the mosquito bite $[2,4,54$, 95]. If sporozoites are injected intravenously, the cryptozoites mainly develop in lymphoid-macrophage cells in various internal organs; they are particularly often seen in the Kupffer cells of the liver and in the lymphoid-macrophage cells of spleen, bone marrow and other organs [5, 10, 53, 55, 73, 91, 97]. Cryptozoites (Fig. 1a-c) look like thin-walled, small roundish bodies, which usually do not exceed $20 \mu \mathrm{m}$ in their largest diameter and produce small number of merozoites (most often fewer than 50). Cryptozoites mature rapidly (approximately between two and three days post-infection). A residual body remains after maturation of cryptozoites of some malaria parasite species $[2,4,61]$. The merozoites developing in cryptozoites are roundish, oval or slightly elongate bodies possessing prominent nuclei (Fig. 1b); they cannot infect the blood cells, so there is no parasitaemia after maturation of the cryptozoites. These merozoites induce the second generation of primary exo-erythrocytic meronts (metacryptozoites), which develop in reticuloendothelial cells, particularly in macrophages, and can be found all over the body; they are often reported in spleen, liver and lungs $[2,7,8,54,55,61,69,74,93,126]$. Metacryptozoites are covered by a thin wall; they look similar to cryptozoites, but are larger and produce a greater number of merozoites (Fig. 1d). Maturation of metacryptozoites is usually asynchronous, and the first parasites mature approximately four to five days post-infection. The merozoites from metacryptozoites are morphologically similar to merozoites from cryptozoites. Metacryptozoites produce merozoites which can: (1) induce further generations of metacryptozoites; (2) initiate development of phanerozoites; and, (3) penetrate the red blood cells and give rise to agamic stages (trophozoites and erythrocytic meronts) and gametocytes. At this stage of malaria, parasitaemia develops and starts to increase, but is often still light. The time from the inoculation of sporozoites into birds until the maturation of the first generation of metacryptozoites is equal to a prepatent period.

Development of the secondary exo-erythrocytic stages (phanerozoites) can be induced in three different ways $[10,54,55,61,64,65,67,69,73,82,91,92,94,97,117$, 127]. First, a proportion of the merozoites from the erythrocytic meronts penetrate the endothelial cells of capillaries and cells of the lymphoid-macrophage system in many organs, including the brain, but particularly often in the spleen and lungs, and produce phanerozoites (Fig. 1e-l). The development of phanerozoites of Plasmodium species can be easily initiated in susceptible birds by merozoites from the erythrocytic meronts, and this feature is often used in experimental research when birds are exposed by the inoculation of infected blood [59, 82, $92,94,117,127]$. Second, a proportion of the merozoites developing in the metacryptozoites induce development of phanerozoites. Third, merozoites from phanerozoites can induce further generations of phanerozoites. It is important to note that the secondary exo-erythrocytic merogony (post-erythrocytic merogony or phanerozoite development) is absent in the malaria parasites of mammals, in which only sporozoites initiate exo-erythrocytic development whether directly, or after a delay, when they are responsible for relapses [11].

Maturation of the first generation of phanerozoites often leads to marked increase of parasitaemia. The first phanerozoites usually mature between 10 days and 3 weeks after infection with sporozoites $[2,4,5,55,61$, 69, 80, 91]. Phanerozoites develop asynchronously, 
resulting in the presence of parasites of different maturity in organs of infected birds (Fig. 1h-j). The morphology of phanerozoites is similar to that of metacryptozoites, but the former usually are larger and contain a greater number of merozoites. Over 100 merozoites usually develop in phanerozoites [4].

Both phanerozoites and erythrocytic meronts produce merozoites, which are responsible for maintenance of parasitaemia during the chronic stage of the infection. In addition, phanerozoites are responsible for relapses [2, $55,69,70,91]$. Because the merozoites from erythrocytic meronts, metacryptozoites and phanerozoites can initiate secondary exo-erythrocytic merogony, the course of secondary exo-erythrocytic development is complicated and difficult to follow stage by stage. The precise number of generations of phanerozoites is unknown, and it probably varies markedly in different species of parasites and avian hosts.

Both the localization and the sequence of appearance of cryptozoites, metacryptozoites and phanerozoites in different organs and tissues varies markedly depending on mode of infection, parasite species, parasite strain characteristics, age of birds, intensity of infection, stage of infection, and some other factors $[4,10,53-55,61,73$, 91, 92, 114, 115, 128].

Exo-erythrocytic meronts (cryptozoites, metacryptozoites, phanerozoites) are covered by a thin wall (Fig. 1a-l). These parasites most often look like roundish or oval bodies containing basophilic cytoplasm and variable numbers of nuclei, which markedly decrease in size as parasites mature (Fig. 1a-e, g-i). The shape of phanerozoites developing in the endothelial cells of capillaries and sinusoids might be determined by the shape of these structures, so they may be elongate, branching or even lobular in shape (Fig. 1j-1); branching and lobular forms particularly occur in brain (Fig. 1j) and muscles. Cytomeres do not usually develop during maturation of exo-erythrocytic meronts of avian Plasmodium parasites.

It is difficult to calculate the number of merozoites in mature exo-erythrocytic meronts because several parasites can develop in one cell or adjacent cells (Fig. 1c), and the boundaries between the parasites are often hardly visible, particularly when parasites are in capillaries (Fig. 1j). The number is very variable however, and fewer than 1000 merozoites usually develop in the exo-erythrocytic meronts of the majority of species of avian malaria parasites. Even young meronts displace the nuclei of infected cells and they can enucleate the host cells, however, they do not usually cause enlargement of nuclei of the host cells (Fig. 1c, g), which is a characteristic feature of exoerythrocytic development of avian malaria parasites.

Two markedly different types of merozoites have been described in phanerozoites: micro- and macromerozoites
(Fig. 1k, l). These have been reported in P. fallax, Plasmodium giovannolai, Plasmodium pinotti and some other species $[2,4,55,65,91,99]$. The micromerozoites predominate in all avian malaria infections; these are small roundish or slightly oval bodies (approximately $1 \mu \mathrm{m}$ in diameter), each possessing a prominent nucleus and a portion of cytoplasm (Fig. 1f, i, k). Macromerozoites are elongate (between 2 and $5 \mu \mathrm{m}$ in length), with slightly curved bodies, and one end often slightly rounded; each merozoite possesses a prominent nucleus, and a tiny vacuole was visible in some parasites (Fig. 11). The role of macromerozoites in the life cycle remains unclear.

The exo-erythrocytic development of the great majority of malaria parasites of subgenera Huffia, Novyella and Bennettinia, remains unknown, or only fragmental data are available, mainly about the development of phanerozoites. The primary exo-erythrocytic meronts (cryptozoites and metacryptozoites) remain undescribed in species belonging to these subgenera because of insufficient experimental research on infections via mosquito bites. Phanerozoites have been reported in some species of these subgenera (Table 1) mainly due to experimental infections, which were induced by inoculation of infected blood.

The exo-erythrocytic merogony of species of subgenus Huffia occurs mainly in cells of the haemopoietic system $[55,56,116,117,120,123,124]$. Phanerozoites (Fig. 1h, i) are especially numerous in migrating cells of haemopoietic tissues in bone marrow and have also been reported in spleen and liver. They develop in erythroblasts, precursor cells of the erythrocytic series, sometimes in normoblasts and thrombocytes and lymphoid cells, but have also been seen in macrophages, myelocytes and some other related cells. Although some reticuloendothelial cells were seen to be parasitized (for example, macrophages), the fixed reticuloendothelial cells have never been recorded to be parasitized, and phanerozoites have not been seen in the endothelial cells of capillaries in brain or other organs in competent avian hosts, in which the Huffia parasites complete their life cycle and produce gametocytes. However, this pattern of development might change during development in non-competent hosts (see description below). Both the size of phanerozoites and the number of merozoites vary markedly in Huffia species depending on their host cells, but the phanerozoite size rarely exceeds $20 \mu \mathrm{m}$ in diameter (Fig. 1h, i). Intracellular growing parasites often are surrounded with a light band of the cytoplasm of host cells, and they possess the basophilic cytoplasm and compact bright-stained nuclei (Fig. 1h). Phanerozoites of $\mathrm{Huf}$ fia species markedly influence the nuclei of host cells (Fig. 1h, i), which is a characteristic feature of the secondary exo-erythrocytic merogony during these infections. 
The nuclei of infected cells are displaced, deformed and may be even pushed out from the cells (Fig. 1h, i). As a result, some phanerozoites appear to be extracellular bodies (Fig. 1h). Several phanerozoites often parasitize the same host cell during heavy infections.

It is important to note that mode of exo-erythrocytic development can change significantly when Huffia parasites appear in non-adapted avian hosts. For example, enormous numbers of Plasmodium (Huffia) elongatum phanerozoites developed in reticuloendothelial cells in the penguin Spheniscus demersus [129]. In this case, the parasite was found not only in cells of haemopoietic system, but also developed extensively in histiocytes of lungs, spleen, liver, heart, and some other organs. Because of changes in both morphology and site of development of the same parasite during development in different avian hosts, it might be difficult to identify species of Plasmodium using morphological characters of exo-erythrocytic meronts, particularly when infection occurs in unusual hosts.

Available experimental data indicate that the extensive exo-erythrocytic merogony usually lasts about a month post infection. After this period, reticuloendothelial cells can develop resistance to infection, the number of phanerozoites decreases and the parasitaemia maintains mainly due to a limited erythrocytic merogony $[2,4,61]$. It is difficult to see phanerozoites in some Novyella species even if parasitaemia is high [2, 4, 130-132]. Recent histological studies, combined with chromogenic in situ hybridization diagnostic tools indicate that exo-erythrocytic development in some tropical Novyella species is mainly primary, and the persistence of infection is due to long-lasting light parasitaemia [133]. In other words, merozoites developing in erythrocytic meronts of these parasites might be unable or have limited ability to produce phanerozoites. This method of persistence might be common in Novyella species, which are widespread, prevalent and diverse in tropical countries [134, 135], but more investigations are required on their exo-erythrocytic development (Table 1). A similar mode of persistence occurs in Plasmodium malariae in humans [11].

Brain damage leading to ischaemic changes is among the most severe pathologies caused by the human malaria parasite Plasmodium falciparum and many species of avian malaria, but the mechanisms of pathology during human falciparum malaria and bird malaria are different $[4,10,12,53,94,136,137]$. Both in birds and humans, cerebral malaria is due to interruption of the circulation in brain vessels (Fig. 2a, b). However, birds are dying because of development of phanerozoites in endothelial cells of the capillaries: the large parasites follow the shape of the vessels, which are eventually completely blocked by the parasites (Fig. 2a). During P. falciparum infection, the infected red blood cells adhere to the endothelial cells of capillaries of the brain (Fig. 2b), leading to interruption of the circulation and resulting in ischaemic brain changes, with similar clinical symptoms and health consequences as is a case of malaria in birds.

\section{Exo-erythrocytic development of avian garniids}

Species of Garniidae are diverse and parasitize many species of reptiles in countries with warm climates. These parasites are similar to species of the Plasmodiidae in that merogony occurs in the cells of fixed tissues and also blood cells of hosts, but malarial pigment (haemozoin) is absent from all stages of their development $[138,139]$. Garniids are absent from temperate and cold climates probably due to lack of specific vectors, which remain unidentified $[6,139,140]$. The development of garniids in their vertebrate hosts is similar to that of Plasmodium species in birds, and some species described as garniids belong to this genus [141]. Molecular characterization is needed to specify taxonomic position of haemosporidian species currently belonging to the Garniidae.

Only one species of the Garniidae, Fallisia neotropicalis is known in birds [4, 142]. In this parasite primary exoerythrocytic meronts, developing from sporozoites have not been reported. Secondary exo-erythrocytic merogony (phanerozoites) can be induced by merozoites developing in the cells of the peripheral blood, as is the case in many species of avian malaria parasites. The phanerozoites look similar to the phanerozoites described in bird malaria parasites. Gabaldon et al. [142] reported that they develop in the reticular cells and in the histiocytes of the connective tissues in many organs including the brain.

It is worth mentioning that there is no DNA sequence information on parasites of the majority of genera and subgenera of the Garniidae, so there is inadequate genetic data to assess their phylogenetic relationships with other haemosporidians. In other words, the entire family is missing from phylogenetic analyses of haemosporidians $[15,17,143]$. That is a shortcoming of the currently available studies on evolution of haemosporidian parasites from the point of view of the limited taxon sampling.

\section{Exo-erythrocytic development of avian haemoproteids}

Approximately 150 species of avian haemoproteids (Haemoproteidae) belonging to the genus Haemoproteus (subgenera Haemoproteus and Parahaemoproteus) have been described [4, 18, 144], and recent molecular studies indicate that many more species probably exist [17]. However, there is, at best, only fragmentary information on exo-erythrocytic development in the great majority of the species (Table 2). Exo-erythrocytic meronts were discovered by Aragão [161] in pigeons naturally infected with Haemoproteus columbae in Brazil. The large 


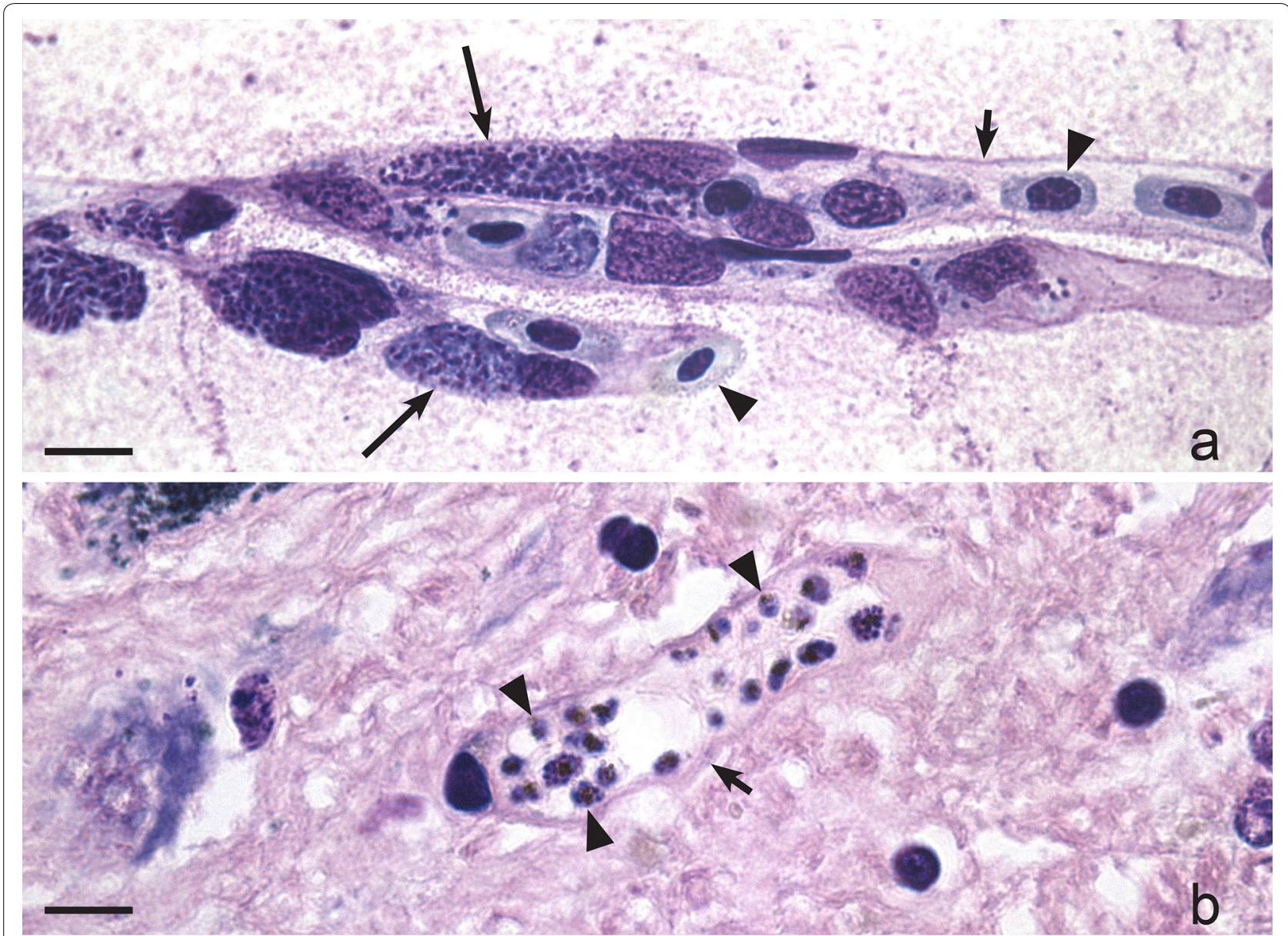

Fig. 2 Cerebral malaria in a chicken (a) and a man (b) due to Plasmodium gallinaceum (a) and Plasmodium falciparum (b) infections, respectively. Note numerous developing and mature phanerozoites in endothelial cells of brain capillaries (a) and numerous infected red blood cells, which adhere to the endothelial cells of a brain capillary (b). In both malaria cases, the circulation interrupts due to blockage of the capillaries by the parasites, and the ischaemic brain changes occur, resulting in severe diseases and similar clinical symptoms, which mechanisms are different. Simple long arrows phanerozoites, simple short arrows wall of capillaries, triangle arrowheads red blood cells. Scale bars $10 \mu \mathrm{m}$

parasites with cytomeres were seen in endothelial cells of lungs. It was concluded that merozoites from these meronts penetrated in the red blood cells and produced gametocytes. That was the first evidence of tissue stages in haemosporidian parasites. In spite of the long history of research, the general patterns of the exo-erythrocytic development of avian Haemoproteus species remains insufficiently understood mainly because of the paucity of experimental studies addressing this issue [5].

Haemoproteids do not multiply in blood cells, and only tissue merogony occurs in birds $[2,4,5,166]$. Two types of the exo-erythrocytic meronts develop (Table 2; Fig. 3a-h): (1) the thick-walled megalomeronts, which usually exceed $100 \mu \mathrm{m}$ and sometimes might reach up to $1000 \mu \mathrm{m}$ in their largest diameter (Fig. 3c-h); and, (2) the thin-walled meronts (Fig. 3a, b), which are smaller (usually less than $50 \mu \mathrm{m}$ ). Morphology of the both types of meronts is markedly variable, and roundish, oval, elongate, branching, and lobular-shaped parasites have been described. Growing megalomeronts and large meronts are usually split into individual portions (cytomeres) (Fig. 3b-e), in which multiplication is continued, and the parasite nuclei are often seen along the edge of developing cytomeres (Fig. 3e). The division of large parasites into cytomeres and the peripheral arrangement of nuclei facilitate metabolic functions. It is important to note that nuclei of host cells are not enlarged either by meronts or megalomeronts of haemoproteids. From this point of view, Haemoproteus parasites are similar to avian Plasmodium species, but are different from Leucocytozoon spp.

Meronts (Fig. 3a, b) and megalomeronts (Fig. 3c-h) are found in various organs, with no clear preference for particular organs or tissues in most well-examined 
Table 2 Exoerythrocytic stages reported in different avian Haemoproteus parasites

\begin{tabular}{|c|c|c|c|}
\hline \multirow{2}{*}{$\begin{array}{l}\text { Subgenus and spe- } \\
\text { cies }\end{array}$} & \multicolumn{2}{|l|}{ Stage } & \multirow[t]{2}{*}{ Reference } \\
\hline & Meront & Megalomeront & \\
\hline \multicolumn{4}{|l|}{ Parahaemoproteus } \\
\hline $\begin{array}{l}\text { Haemoproteus } \\
\text { attenuatus }\end{array}$ & + & $-^{a}$ & {$\left[66^{b}, 145\right]$} \\
\hline H. balearicae & + & - & {$[146]$} \\
\hline H. coatneyi & + & - & {$[147]$} \\
\hline H. halcionis & - & + & [148] \\
\hline H. handai & + & + & [149] \\
\hline H. lophortyx & & + & {$[20]$} \\
\hline H. mansoni & + & + & {$[150,151]^{c}$} \\
\hline H. minutus & & + & {$[23,26]$} \\
\hline H. nettionis & + & - & {$[152]$} \\
\hline H. orizivorae & + & - & [153] \\
\hline H. passeris & + & + & [154-157] \\
\hline H. picae & + & - & {$[158]^{d}$} \\
\hline H. sacharovi & - & + & {$[5,31]$} \\
\hline \multicolumn{4}{|l|}{ Haemoproteus } \\
\hline H. columbae & + & + & $\begin{array}{c}{[41,132,148,157,} \\
159-164]\end{array}$ \\
\hline H. palumbis & + & - & {$[165]$} \\
\hline
\end{tabular}

Only parasites, which species identification was supported by morphological or molecular identifications were included in this table. Reports of unidentified parasites or the parasites of undetermined or questionable taxonomic status were not included. To date, approximately 150 avian Haemoproteus species were described, and 945 lineages of these parasites were reported (according to MalAvi database, http://mbio-serv2.mbioekol.lu.se/Malavi)

${ }^{a}$ Exoerythrocytic stages were not seen

b Garnham, Duggan [66] attributed this parasite to Haemoproteus danilewskii

c Originally identified as $H$. meleagridis, which possibly is a synonym of $H$. mansoni (see [4])

${ }^{d}$ Garvin et al. [158] attributed this parasite to Haemoproteus danilewskii

Haemoproteus and Parahaemoproteus species (Table 3). However, there are exceptions. For example, the exoerythrocytic merogony of Haemoproteus mansoni (syn. Haemoproteus meleagridis), Haemoproteus handai and
Haemoproteus lophortyx is often seen in skeletal muscle tissues (Fig. $3 \mathrm{f}-\mathrm{h}$ ), and this preference is confirmed by experimental infections [20, 149-151]. Limited available data indicate some patterns of exo-erythrocytic development in certain haemoproteid species, but they might be different in different parasites. That needs additional investigation because much information comes from single or few naturally infected birds, with unclear origin or fluctuations of the infections through time [31, 41, 43, $145,148,155,157,159,164,167,168]$.

Megalomeronts (Fig. 3c-h) were described in several species of Parahaemoproteus and Haemoproteus (Table 2). These parasites seriously damage affected organs and tissues (Fig. 3e, f), particularly after their maturation and rupture. Megalomeronts of various parasite species have been seen in the skeletal muscle, heart, gizzard, lungs, liver, spleen, kidney, and proventriculus of their hosts [20,21,31,41, 149, 154, 155, 157, 168]. Atkinson et al. $[150,151]$ reported that skeletal muscles were particularly often parasitized during experimental H. mansoni infection in domestic turkeys (Fig. $3 \mathrm{f}-\mathrm{h}$ ) however, the megalomeronts were also recorded in cardiac muscle. Interestingly, the $H$. mansoni megalomeronts were not seen in the liver, lungs, brain, kidney, bone marrow, femur, gizzard, duodenum, pancreas, or cecum. Most of these organs, especially lungs and brain, are highly vascular. This suggests a specific requirement for myofibroblasts or their associated physiological environment for the development of megalomeronts. Miltgen et al. [149] also found megalomeronts predominantly in muscle tissues, in the heart, tongue, hip and pectoral muscle; these were especially numerous in the pectoral muscle. Megalomeronts of $H$. minutus developed in myocardial and skeletal muscles and some other organs of captive parakeets, and the infection was lethal in these avian hosts $[23,26]$.

Due to their size, the largest megalomeronts can sometimes be seen without a microscope, on the surface of

(See figure on previous page.)

Fig. 3 Exo-erythrocytic stages of Haemoproteus parasites: meronts $(\mathbf{a}, \mathbf{b})$ and megalomeronts $(\mathbf{c}-\mathbf{h})$. Small mature meront of Haemoproteus palumbis in lungs of a naturally infected nestling of the English wood-pigeon Columba palumbis (a). Group of maturing meronts of Haemoproteus attenuatus in lungs of a naturally infected European robin Erythacus rubecula (note numerous irregular-shaped cytomeres with developing merozoites, b). Numerous developing megalomeronts of Haemoproteus passeris in a section of liver in a naturally infected House sparrow Passer domesticus (note that megalomeronts tend to group, and each megalomeront is covered by a wall and contains several cytomeres, $\mathbf{c}$ ). A maturing megalomeront of H. passeris (the same preparation as in $\mathbf{c}$; note that the parasite is covered by a thick wall and contains seven well-defined cytomeres, which are covered by a thin membrane and contain numerous irregularly shaped subcytomeres with developing merozoites, d). Two maturing cytomeres of $H$. passeris (the same preparation as in $\mathbf{c}$; note that the cytomeres separate from each other before maturation, and nuclei locate on the edge of subcytomeres, e). Mature oval megalomeront of Haemoproteus mansoni (syn. Haemoproteus meleagridis) in the section of the pectoral muscle of a turkey Meleagris gallopavo (note that megalomeront is surrounded by thick wall and is overfilled with roundish merozoites; the muscle fibres surrounding the parasite are swollen and pale-stained, f). Rupturing mature roundish megalomeront of $H$. mansoni (the same preparation as in $\mathbf{f}$; note the swollen tissue surrounding the parasite, $\mathbf{g}$ ). Mature lobular-shape megalomeront of H. mansoni (the same preparation as in $\mathbf{f}$; note irregular outline of the parasite, $\mathbf{h}$ ). Simple long arrows meronts, simple wide long arrows megalomeronts, triangle long arrows parasite nuclei, triangle wide long arrows cytomeres, simple wide short arrows subcytomeres, simple short arrows megalomeront wall. Scale bars $10 \mu \mathrm{m}(\mathbf{a}, \mathbf{b}, \mathbf{e}), 50 \mu \mathrm{m}(\mathbf{c}, \mathbf{d}, \mathbf{f}-\mathbf{h})$ 


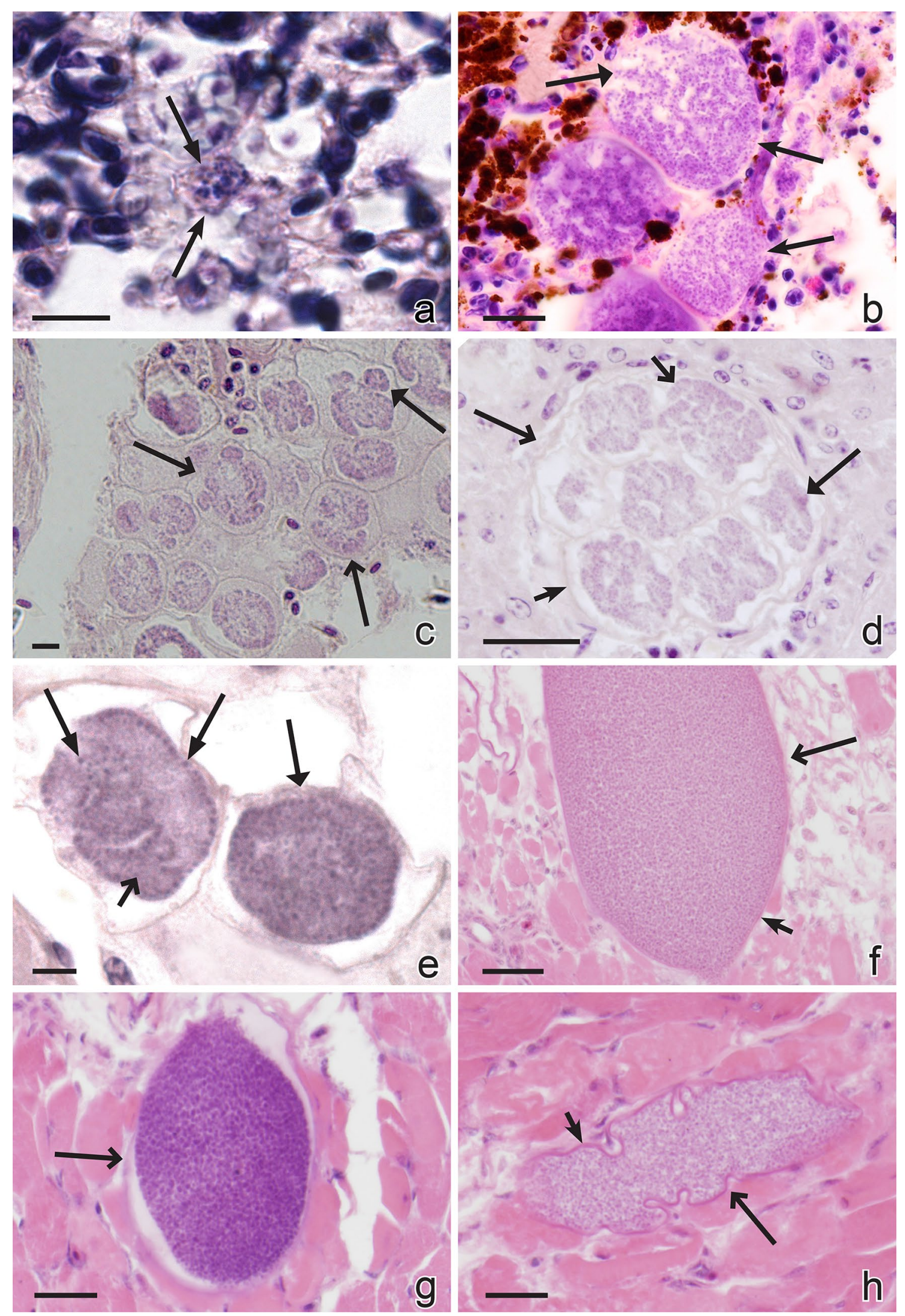


Table 3 Location of exoerythrocytic stages in different avian haemoproteids

\begin{tabular}{|c|c|c|}
\hline \multirow[t]{2}{*}{ Location of tissue meronts } & \multicolumn{2}{|c|}{ Parasite subgenus and species } \\
\hline & Haemoproteus & Parahaemoproteus \\
\hline Lungs & H. columbae, H. palumbis & $\begin{array}{l}\text { H. attenuatus, } H \text {. balearicae, } H \text {. coatneyi, } H \text {. nettionis, } H \text {. orizivorae, } H \text {. } \\
\text { passeris, } H \text {. picae, } H \text {. sacharovi }\end{array}$ \\
\hline Spleen & H. columbae & $\begin{array}{l}\text { H. attenuatus, H. coatneyi, H. lophortyx, H. mansoni, H. nettionis, } H \text {. } \\
\text { picae }\end{array}$ \\
\hline Heart & H. columbae, H. palumbis & H. coatneyi, H. handai, H. mansoni, H. minutus, H. nettionis \\
\hline Liver & H. columbae & H. coatneyi, H. passeris, H. picae \\
\hline Skeletal muscles (particularly often in pectoral muscle) & H. columbae & H. halcionis, H. handai, H. mansoni, H. lophortyx \\
\hline Kidneys & H. columbae & H. coatneyi, H. passeris \\
\hline Proventiculus & H. columbae & H. handai \\
\hline Gizzard & H. columbae & H. sacharovi \\
\hline Caecum & $-^{a}$ & H. coatneyi \\
\hline Tongue & - & H. handai \\
\hline Hip & - & H. handai \\
\hline
\end{tabular}

References for a given parasite species are the same as in Fig. 2. Only parasites, which species identification was supported by morphological or molecular identifications were included in this table. Reports of unidentified parasites or the parasites of undetermined or questionable taxonomic status were not included

${ }^{a}$ Exoerythrocytic stages were not seen

damaged organs [5, 31]. Large parasites are surrounded by a thick hyaline wall (Fig. 3d, f, h). Cytomeres are well defined in developing megalomeronts (Fig. 3d), and nuclei are typically arranged on the periphery of developing cytomeres (Fig. 3i). Megalomeronts are often seen located close to each other, forming large groups (Fig. 3c).

The number of generations of exo-erythrocytic meronts before development of parasitaemia has only been sufficiently documented in $H$. mansoni, in which at least two generations of the meronts develop in the skeletal and cardiac muscles before the parasite produce merozoites that are able to invade red blood cells $[150,151]$. First-generation meronts were seen in the endothelium of capillaries and in myofibroblasts of experimentally infected domestic turkeys. They matured approximately 5 days after infection with sporozoites. The mature parasites can reach up to $20 \mu \mathrm{m}$ in largest diameter and contain elongate merozoites, which are 5-6 $\mu \mathrm{m}$ in length. The elongate merozoites induce the next generation of merogony in the endothelial cells of the capillaries and in myofibroblasts and also initiate development of meronts in the reticular cells of the spleen. The meronts of the second generation are megalomeronts, which are covered by a hyaline wall (Fig. 3f, h). Megalomeronts mature approximately 17 days after infection and produce numerous roundish merozoites with a diameter of about $1 \mu \mathrm{m}$. The merozoites formed in megalomeronts penetrate into red blood cells and become gametocytes.

The overall number of generations of meronts after single-sporozoite infections is unknown in avian haemoproteids, but there are certainly many generations because infected birds usually maintain parasitaemia for many years in controlled laboratory conditions. Additionally, the spring relapses, which are induced by dormant tissue meronts were reported in avian haemoproteids $[2,4,5]$. Available data indicate that meronts of H. mansoni, causing relapses and maintaining chronic parasitaemia in turkeys, develop in reticular cells of the spleen [151].

It is important to note that avian haemoproteids can develop tissue stages in 'wrong' avian hosts, in which sporozoites initiate exo-erythrocytic development, which is then arrested (aborted), so merozoites and gametocytes do not appear. Such abortive infections might be virulent and even lethal in non-adapted avian hosts, but remain insufficiently investigated. Recent PCR-based studies [21-23] have supplemented earlier histopatology research $[41,151]$ and provided first real evidence that species of Haemoproteus and Parahaemoproteus are responsible for disease and even mortality in birds. It was shown that common species and lineages of Haemoproteus parasites might be relatively benign in naturally adapted hosts, but cause lethal disease in non-adapted birds due to damage of organs by megalomeronts [2123, 26, 41]. The tissue stages of Haemoproteus species in dead hosts resemble the megalomeronts of Leucocytozoon spp.; it was difficult to determine the disease etiology solely based on morphological data [33-35, 38, 39, 42-44, 169-172]. The traditional opinion about the harmlessness and insignificant veterinary importance of avian haemoproteids [44] requires partial reconsideration $[21,22,26,30]$. The true extent of pathology and mortality caused by Haemoproteus parasites requires 
additional investigation, particularly in wildlife because death of infected birds has been reported before the development of parasitaemia. Such disease is difficult to diagnose using blood samples alone, whether either by microscopy or PCR-based tools. Experimental studies are needed, but remain rare because of their difficult design, which requires laboratory manipulations of wild birds and obtaining live sporozoites. In haemoproteids, the latter can mainly be collected by experimental infection of biting midges and hippoboscid flies.

Application of a chromogenic in situ hybridization (ISH) method for detection of tissue meronts in bird organs might be helpful during investigation of exoerythrocytic merogony of haemosporidians, as is the case in avian Plasmodium parasites [22, 45, 94]. This method speeds up the search for tissue stages of malaria parasites, but has not been used in diagnosis of leucocytozoids and has been rarely applied in avian haemoproteid research [22]. It is important to note that the traditional histology techniques remain informative in haemosporidian parasite morphology research and are useful for better understanding pathologies caused by haemoproteid infections in different organs and tissues (Fig. 3). It worth using these methods in parallel during investigation of exo-erythrocytic development of haemosporidian parasites [94].

\section{Exo-erythrocytic development of avian leucocytozoids}

Approximately 40 species of avian leucocytozoids have been described. These parasites do not multiply in blood cells, and only tissue merogony occurs, as is the case in Haemoproteus parasites $[2,4,166,173]$. The exo-erythrocytic meronts have been found and described in 14 leucocytozoid species (Table 4), and merogony was studied particularly well in several species of subgenus Leucocytozoon (Leucocytozoon danilewskyi, Leucocytozoon fringillinarum, Leucocytozoon dubreuili, Leucocytozoon simondi, Leucocytozoon smithi) and one species of Akiba (Leucocytozoon caulleryi) using sporozoite-induced infections [162, 177, 179, 195, 197, 199, 202, 206, 209, 211, 217, 221, 226]. The exo-erythrocytic development occurs in the parenchymal cells of the liver (hepatocytes), in tubular cells of kidneys, in macrophages and various other reticuloendothelial cells, including endothelial cells of the capillaries.

Several generations of tissue meronts develop in all experimentally examined Leucocytozoon species but the precise number of generations remains unclear $[4,173$, 176, 179, 190, 197-199, 206, 211, 226]. The sporozoites initiate exo-erythrocytic development in the parenchymal cells of the liver, in which the hepatic meronts of the first generation grow (Fig. 4a, b). The primary hepatic merogony inside hepatocytes is a general pattern in the
Table 4 Exoerythrocytic stages reported in different avian Leucocytozoon parasites

\begin{tabular}{|c|c|c|c|}
\hline \multirow{2}{*}{$\begin{array}{l}\text { Subgenus and spe- } \\
\text { cies }\end{array}$} & \multicolumn{2}{|l|}{ Stage } & \multirow[t]{2}{*}{ Reference } \\
\hline & Meront & Megalomeront & \\
\hline \multicolumn{4}{|l|}{ Leucocytozoon } \\
\hline $\begin{array}{l}\text { Leucocytozoon arta- } \\
\text { midis }\end{array}$ & + & + & {$[174]$} \\
\hline L. berestneffi & + & $-{ }^{a}$ & {$[4,175,176]$} \\
\hline L. danilewskyi & + & + & [177] \\
\hline L. dubreuili & + & - & [178-180] \\
\hline L. fringillinarum & + & - & [179] \\
\hline L. lovati & + & + & [181-183] \\
\hline L. macleani & + & - & {$[184,185]$} \\
\hline L. marchouxi & - & + & [186] \\
\hline L.podargii & - & + & [187] \\
\hline L. sakharoffi & + & + & {$[176,188-192]$} \\
\hline L. simondi & + & + & {$[162,166,193-209]$} \\
\hline L.smithi & + & - & [210-213] \\
\hline L. tawaki & + & - & {$[214,215]$} \\
\hline \multicolumn{4}{|l|}{ Akiba } \\
\hline L. caulleryi & + & + & {$[216-227]$} \\
\hline
\end{tabular}

Only parasites, which species identification was supported by morphological or molecular identifications were included in this table. Reports of unidentified parasites or the parasites of undetermined or questionable taxonomic status were not included. To date, approximately 40 Leucocytozoon species were described, and 694 lineages of these parasites were reported (according to MalAvi database, http://mbio-serv2.mbioekol.lu.se/Malavi)

a Exoerythrocytic stages were not seen

exo-erythrocytic development of species of the subgenus Leucocytozoon. From this point of view, species of this subgenus are more similar to malaria parasites of mammals than to avian Plasmodium, Haemoproteus or Akiba parasites $[4,11]$. In L. smithi, exo-erythrocytic merogony takes place only in parenchymal cells of the liver [201, 211, 213]. However, in other Leucocytozoon species various organs and tissues can be affected, particularly by subsequent (induced by merozoites) generations of tissue meronts. In L. simondi, the first generation of tissue meronts develop only in hepatocytes (Fig. 4a, b), and only subsequent generations of meronts appear in other organs and cells. In L. dubreuili and L. fringillinarum, sporozoites initiate development of meronts in liver, but also in kidneys where they locate in renal tubular cells [177-180]. As meronts grow, nuclei of the host cells increase in size and the cytoplasm breaks down into numerous cytomeres, in which nuclear fission continues (Fig. 4b). The development of first generation meronts is completed four to five days post infection. Numerous uninuclear merozoites develop in each cytomere. It is important to note that the hepatic meronts usually do not induce marked enlargement of nuclei in hepatocytes (Fig. 4b). Mature meronts are very variable in size, but 
are usually smaller than $50 \mu \mathrm{m}$ in diameter; they produce merozoites, which are roundish bodies of approximately $1-2 \mu \mathrm{m}$ in diameter. Merozoites invade various blood cells producing the gametocytes. Some merozoites also initiate new generations of meronts in liver and the kidneys. The hepatic and renal merogonies are not synchronized, and young growing meronts may be seen together with the mature parasites.

During $L$. dubreuili infection, some of the sporozoites invade liver parenchymal cells and produce small (about $6 \mu \mathrm{m}$ in largest diameter) oocyst-like meronts, which produced elongate (cystozoite-like) merozoites germinating from a single germinal centre [178]. These meronts are probably persistent (dormant) stages, which are responsible for relapses; they have not been reported in other Leucocytozoon parasites.

After rupture of the hepatic meronts, the cytoplasmic 'fragments' develop in parallel with merozoites. These fragments are called the syncytia (islands); they are covered by a plasma membrane and contain several nuclei $[166$, 173, 198]. Syncytia are remnants of the meronts. They are unable to penetrate into host cells, but are washed out into the circulation, spread over the bird body and are phagocytized by macrophages and other cells of the reticuloendothelial system giving rise to large merontsmegalomeronts (megaloschizonts) (Fig. 4c-h). The term megalomeront (megaloschizont) was suggested by Huff [162] for the 'host cell-Leucocytozoon parasite' complex. The markedly enlarged nucleus of the host-cell ('central body' of megalomeront) is the most readily distinguishable character of megalomeronts in Leucocytozoon species (Fig. 4c-h). The central body is often located close to the centre of megalomeronts (Fig. 4d, g, h). Syncytia grow rapidly and induce marked enlargement both of the nuclei and the cytoplasm of host cells. Numerous cytomeres appear (Fig. $4 \mathrm{~d}-\mathrm{f}$ ). As the parasite matures, each cytomere breaks up into numerous smaller bladder-like portions (subcytomeres, Fig. 4d, e, g), with the nuclei often located on the surface of the subcytomeres. Subdivision of smaller cytomeres continues until uninuclear merozoites appear. Both the division of parasite into cytomeres and the peripheral arrangement of nuclei in the cytomeres facilitate the metabolic and trophic functions. Nuclei of host cells, which contain mature megalomeront, might reach $50-100 \mu \mathrm{m}$ in diameter and even greater (Fig. 4d, g). The greatly enlarged nucleus of the host cell (the 'central body' of megalomeront) probably takes part in transportation of nutrient materials inside the parasites. Growth of megalomeronts from their initiation to maturity represents a several 1000-fold increase in volume. Mature megalomeronts are packed with numerous merozoites, and boundaries between the cytomeres gradually disappear.

Megalomeronts are surrounded with a thick capsulelike wall of fibrillar structure, which is collagen-positive $[166,173,195,198]$. The wall can be about $1 \mu \mathrm{m}$ in width or even thicker. The encapsulation is most obvious in organs with a dense reticular network such as the spleen and lymph nodes (Fig. 4d, e), and it is least in the brain and heart (Fig. 4f). Growing megalomeronts displace surrounding cells and reticular fibres, which become associated with the surface of the expanding sphere and thus take part in the formation of the capsular wall.

Mature megalomeronts are very variable in size, which usually ranges between 50 and $500 \mu \mathrm{m}$, but might be even greater. The largest megalomeronts can be seen with the naked eye on the surface of heavily infected organs [4, $166,173,195]$. It is likely that size of mature megalomeronts partially depends to the size and number of syncytia, which are phagocytized by host cells $[166,195,199$, 202]. Development of megalomeronts is asynchronous due to asynchronous phagocytosis of syncytia in different organs (Fig. 4c).

(See figure on next page)

Fig. 4 Exo-erythrocytic stages of Leucocytozoon parasites: meronts $(\mathbf{a}, \mathbf{b})$ and megalomeronts (c-h). Hepatic meronts of Leucocytozoon simondi in a liver section of an experimentally infected Pekin duck Anas platyrhynchos domestica (note numerous meronts and the much haemorrhagic and disorganized liver tissue, a). Maturing hepatic meront of L. simondi (the same preparation as in a; note numerous cytomeres, in which division of parasite nuclei occurs and non-changed size of the infected hepatocyte nucleus, in comparison to nuclei size in the adjacent non-infected hepatocytes, b). Megalomeronts of Leucocytozoon sakharoffi in different stages of growth in spleen of a naturally infected the hooded crow Corvus cornix (note numerous roundish megalomeronts in different stages of growth, $\mathbf{c}$ ). Maturing megalomeront of $L$. sakharoff (the same preparation as in $\mathbf{c}$; note a markedly enlarged host cell nucleus or the 'central body' of megalomeront, capsular-like wall surrounding the parasite, and numerous cytomeres, d). A fragment of the $L$. sakharoff megalomeront (the same preparation as in $\mathbf{c}$; note cytomeres containing numerous roundish subcytomeres, in which nuclear division occurs, a well-evident 'central body' and capsular-like wall surrounding the megalomeront, e). Megalomeront of $L$. simondi in hart of a naturally infected mallard Anas platyrhynchos (note numerous cytomeres, a well-evident 'central body', and capsular-like wall, f). Megalomeront of Leucocytozoon sp. in a section of spleen in a naturally infected Australian magpie Cracticus tibicen (note a large 'central body' and numerous roundish cytomeres in a parasite developing in a vessel, $\mathbf{g}$ ). Megalomeront of Leucocytozoon sp. in a section of skeletal muscle of a naturally infected tawny frogmouth Podargus strigoides (note a large 'central body' and numerous roundish developing cytomeres; the muscle fibres surrounding the parasite are swollen, $\mathbf{h}$ ). Simple long arrows meronts, simple wide long arrows megalomeronts, triangle wide long arrows cytomeres, simple wide short subcytomeres, simple short arrows megalomeront wall, triangle wide short arrow a nucleus of infected hepatocyte, simple arrowhead a nucleus of non-infected hepatocyte, stars host cell nucleus or 'central body' of megalomeront. Scale bars $10 \mu \mathrm{m}(\mathbf{b}), 50 \mu \mathrm{m}(\mathbf{a}, \mathbf{d}-\mathbf{h}), 200 \mu \mathrm{m}$ (c) 

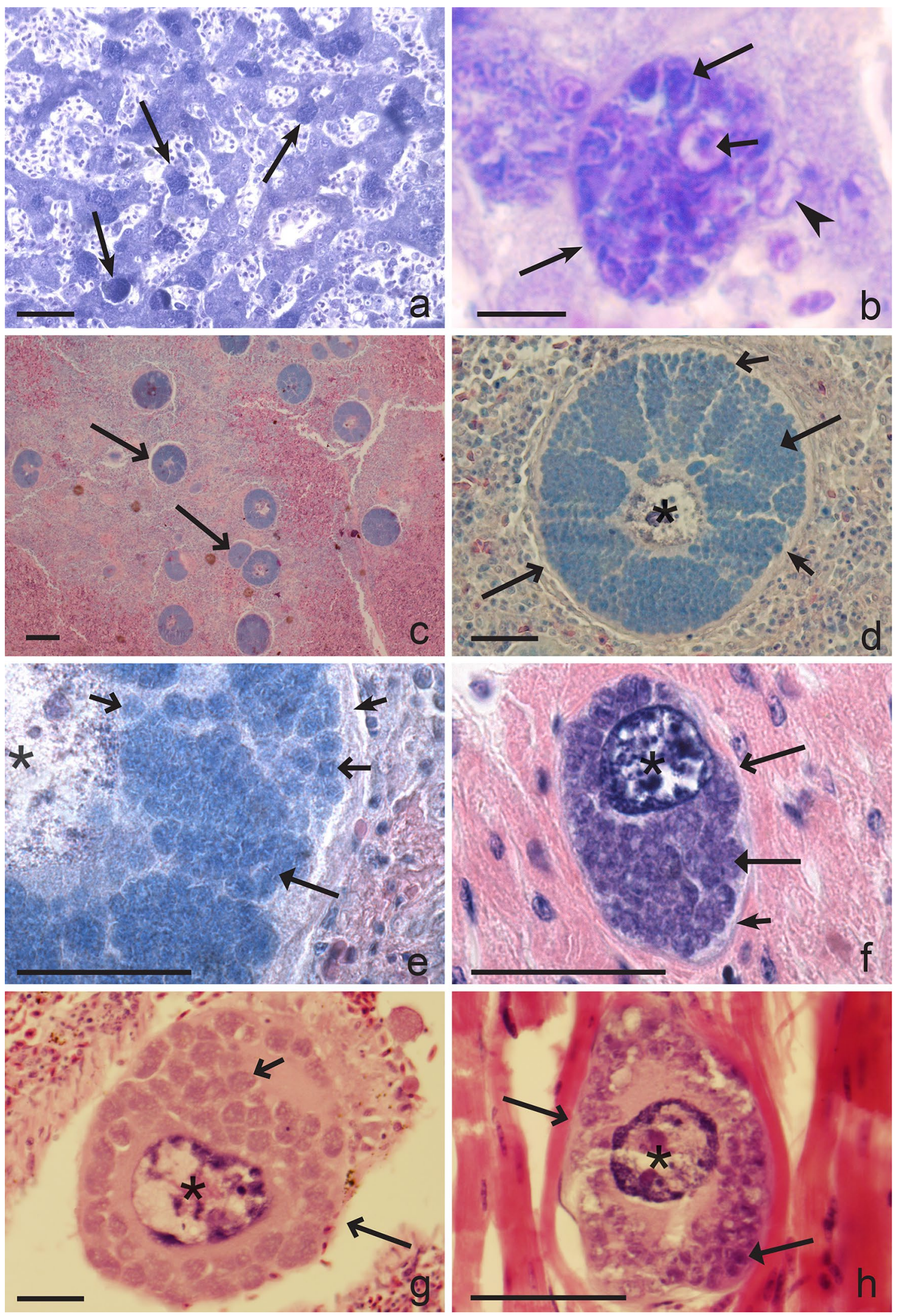
Megalomeronts have been reported all over body in the infected birds, including brain, nerves, heart, pericardium, lungs, trachea, kidneys, liver, pancreas, intestine, skeletal muscles, masticatory, and glandular parts of stomach, gonads, bursa of Fabricius, but most often seen in the spleen (Fig. 4c-e) and the lymph nodes [162, 166, $173,186,191,192,195,205]$. Intensity of infection in the latter two organs can be extremely high (Fig. 4c), and the parasites can represent over $50 \%$ of the infected spleen mass. The marked enlargement of spleen is sometimes due to the megalomeronts mass per se during intense Leucocytozoon infection [195], and such mechanism of spleen enlargement has not been recorded in any other haemosporidiosis. It should be noted that megalomeronts are usually uncommon in the liver, which is the site of extensive phagocytosis in birds. It seems that the absence or rarity of megalomeronts in the liver is due to local immunity induced after intense primary hepatic merogony (Fig. 4a), and the destruction of syncytia in the Kupffer cells.

Megalomeronts develop rapidly and become mature approximately four to five days after ingestion of syncytia by their host cells or approximately 7-9 days following a sporozoite infection [166, 195, 200, 202]. Many thousands of uninuclear merozoites develop in each megalomeront. The merozoites are approximately of $1 \mu \mathrm{m}$ in diameter; they inhabit various blood cells and produce gametocytes.

Some of the merozoites formed in megalomeronts are phagocytized by the reticuloendothelial cells and slow down their development, periodically producing megalomeronts, which are responsible for the chronic parasitaemia and also spring relapses [208, 209]. Persisting meronts are few and usually difficult to find. They were seen in lungs during $L$. simondi infection [199].

Small meronts develop in all species of leucocytozoids, but megalomeronts do not. The latter were reported in L. danilewskyi, Leucocytozoon sakharoffi, L. simondi, L. caulleryi and in some other species (Table 4). Megalomeronts were not found in L. dubreuili, L. fringillinarum, L. smithi and many other species. The role of megalomeronts in the life cycle of leucocytozoids is insufficiently understood. In L. simondi and L. danilewskyi, the merozoites from megalomeronts inhabit blood cells and initiate the development of gametocytes, which markedly change the host cells by producing elongate host cell processes $[177,228]$. However, there is no strict correlation between the development of megalomeronts and the appearance of gametocytes in the fusiform host cells in other leucocytozoid species. For example, gametocytes do not develop in fusiform host cells in Leucocytozoon artamidis, L. caulleryi, Leucocytozoon marchouxi, Leucocytozoon podargii and L. sakharoffi, although these species do produce megalomeronts in some avian hosts [174, 186, 187, 191, 192, 226], while such gametocytes predominate in $L$. smithi, in which megalomeronts are absent [211]. Additional investigations are needed to understand the role of megalomeronts in the life cycle of leucocytozoids.

Exo-erythrocytic merogony of L. (Akiba) caulleryi differs from the species of subgenus Leucocytozoon in several characters [216, 218, 221, 224, 226]. First, the meronts of the first and following generations do not develop in hepatic cells. This feature is more similar to species of Plasmodium and Haemoproteus than to species of Leucocytozoon. All generations of meronts of $L$. caulleryi grow in the endothelial cells of the capillaries of many organs and can be found in brain, bursa of Fabricius, thymus, trachea, bronchus, lungs, heart, liver, spleen, kidneys, pancreas, gullet, masticatory and glandular stomach, crop, duodenum, ovary, testis, oviduct, and various skeletal muscles. It is interesting to note that they occur not only in the visceral organs but also in the eyes and sciatic nerves [219]. The meronts of $L$. caulleryi were especially numerous and often seen in bursa of Fabricius and thymus.

Second, merozoites developing in meronts of the first generation are elongate (up to $7 \mu \mathrm{m}$ in length) and are similar morphologically to the first generation merozoites described in $H$. mansoni $[5,223,226]$.

Third, megalomeronts complete their development extracellularly and they do not have the 'central body' [221, 223, 224, 226, 228]. Extracellular development occurs when the infected cells rupture, and growing megalomeronts containing numerous cytomeres are released from the cells (Fig. 5a, b). Extracellular developing megalomeronts (Fig. 5b) are seen in many organs and tissues. Megalomeronts may be solitary or in groups (Fig. 5a), and they complete maturation extracellularly, a unique character in described haemosporidian parasites. Large megalomeronts can reach more than $300 \mu \mathrm{m}$ in diameter [221, 222]. The size of megalomeronts depends on their location. Solitary megalomeronts are usually larger than the parasites developing in clusters [220]. Megalomeronts are enclosed within a well-defined envelope (Fig. 5a). The host-cell nucleus is enlarged and, if present in growing megalomeronts, is located on the edge of the cytomeres, but not within the cytomere masses, as is the case in megalomeronts of Leucocytozoon species (compare Figs. $4 d-h, 5 b)$.

\section{Discussion}

In spite of limited knowledge about the exo-erythrocytic development in many species of haemosporidian parasites, some basic morphological characters of the tissue meronts indicate their generic or subgeneric identity. 

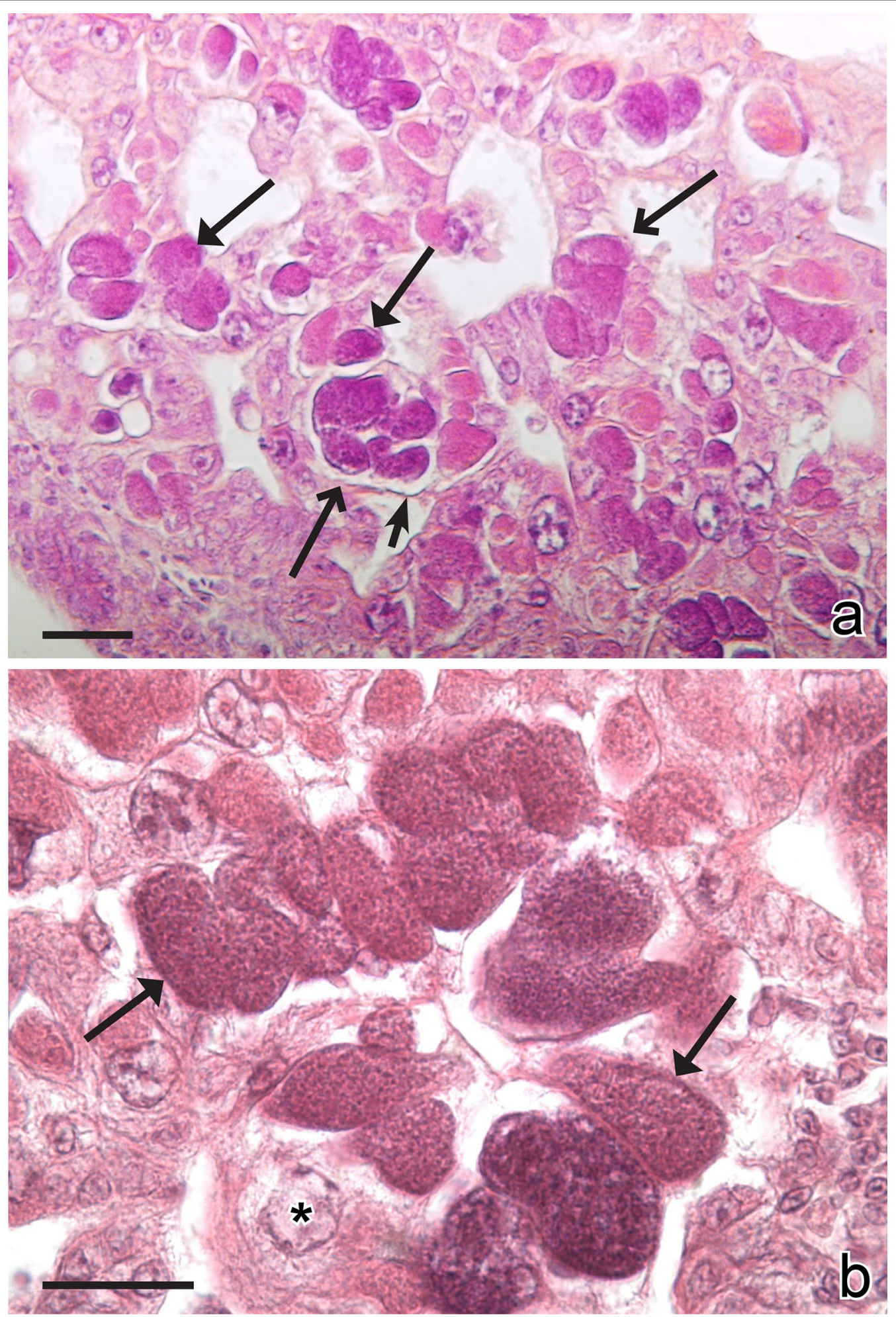

Fig. 5 Developing megalomeronts of Leucocytozoon (Akiba) caulleryi in a kidney section of an experimentally infected domestic chicken Gallus gallus domesticus $(\mathbf{a}, \mathbf{b})$. Note numerous maturing extracellular cytomeres; developing megalomeronts are enclosed within a well-defined envelope (a). Host-cell nuclei are slightly enlarged and, if seen, locate on edge of the cytomere masses (b). Simple wide long arrows megalomeronts, triangle wide long arrows cytomeres, simple short arrow megalomeront envelope, star host cell nucleus of megalomeront. Scale bars 50 um 
Table 5 Main morphological characters of exoerythrocytic meronts of avian haemosporidian parasites

\begin{tabular}{|c|c|c|c|c|}
\hline Character & Plasmodium & Haemoproteus & Leucocytozoon & Akiba \\
\hline Merogony in hepatocytes (Fig. 4a, b) & Absent & Absent & Present & Absent \\
\hline Merogony in cells of hemopoietic system (Fig. 1h, i) & Present & Absent & Absent & Absent \\
\hline Thin-walled elongate meronts in brain capillaries (Fig. 1j-l) & Present & Absent & Absent & Absent \\
\hline Megalomeronts (Fig. 3c-h, Fig. 4c-h, Fig. 5a, b) & Absent & Present & Present & Present \\
\hline 'Central body' in megalomeronts (Fig. 4d-h) & Absent & Absent & Present & Absent \\
\hline Extracellular development of megalomeronts (Fig. 5a, b) & Absent & Absent & Absent & Present \\
\hline $\begin{array}{l}\text { Prominent (more than threefold in comparison to controls) } \\
\text { enlargement of host cell nuclei (Fig. } 4 \mathrm{~d}, \mathrm{f}-\mathrm{h} \text { ) }\end{array}$ & Absent & Absent & Present & Absent \\
\hline
\end{tabular}

Absence of a given character in examined parasite preparations might be due to inappropriate stage of parasite development or other methodology issues, and should be treated with caution in practical work. Presence of a given character in preparations indicates taxonomic status of haemosporidians

During mammalian malaria, exo-erythrocytic development occurs in hepatic cells

These characters are given in Table 5 and can be helpful for determining the taxonomic status of tissue stages in histological preparations of organs and tissues, particularly in samples collected from naturally infected birds.

This review shows that the exo-erythrocytic development of the majority of species of wildlife haemosporidian parasites remains unknown or studied only fragmentally (Tables 1, 2 and 4), most often using incidentally collected samples from wild, naturally infected birds, in which the fate and duration of these infections is unclear. Molecular diagnostic tools have opened new opportunities to detect infections and to determine parasite species identity in tissue stages, providing the first real evidence that these avian parasites are more virulent than formerly believed, causing severe damage in various organs of non-adapted avian hosts [21, 22, 26, $29,30,94]$.

It is important to note that the exo-erythrocytic merogony of a given strain of haemosporidian parasites may differ significantly in different avian hosts, sometimes resulting in abortive development and increase of virulence of parasites in 'wrong' hosts. This phenomenon is well documented, but its mechanisms remain insufficiently understood. For example, extensive exo-erythrocytic development of $P$. elongatum in non-adapted penguins occurs not only in cells of haemopoietic system, as usually is the case in adapted passerines, but also in reticuloendothelial cells, resulting in the intense merogony, the marked damage of various organs and severe disease, during which parasitaemia might be absent [4, 129]. Similar abortive exo-erythrocytic development occurs in $H$. minutus infection of captive parakeets, in which sporozoites produce megalomeronts that cause lethal disease, but parasitaemia is absent as well [23, 26]. The lethal aberrant avian haemosporidioses caused by tissue stages have been reported in various bird species, using of PCR-based diagnostic methods in Europe,
America and Australia [20-26]. Available molecular data leave no doubt that aberrant haemosporidian infections may kill non-adapted avian hosts. However, it is unclear how often that happens in wildlife and what are the consequences of such infections for bird populations.

Many haemosporidian species and their lineages have broad specificity and can infect birds belonging to different species, genera, families, and even orders $[4,5,13,14$, $16,19]$. The exo-erythrocytic development of a given species of avian haemosporidian can be different in different avian hosts. In other words, the sequence of different stages and their occurrence during the exo-erythrocytic development of a particular parasite strain are not stable characteristics, but they can be functions of the host species. For example, experimental studies showed marked differences in the exo-erythrocytic development of the same strain of Leucocytozoon in different vertebrate hosts [200, 201]. Mainly, a strain of $L$. simondi developed megalomeronts in ducks, but not in geese. Complete exoerythrocytic development occurred only ducks. In both species of avian hosts, the infective for vectors stages (gametocytes) developed. The 'partial' exo-erythrocytic development in geese was accompanied by reduced parasitaemia and virulence of this parasite strain. Moreover, the parasite was finally eliminated from infected geese, resulting in lack of relapses, which was not the case in ducks, in which long-lasting parasitaemia and relapses occurred. It seems that ducks are less adapted to some strains of $L$. simondi, resulting in development of megalomeronts and heavy disease. During development in geese, the same strain undergoes only the 'partial' development, and megalomeronts do not occur. This finding was supported experimentally by exposure of ducks and geese to natural infection of $L$. simondi at different localities in the upper peninsula of Michigan [200]. Interestingly, $L$. sakharoffi is cosmopolitan and infects many species of the Corvidae, but megalomeronts were 
reported only in the hooded crow Corvus cornix [4, 192]. Additionally, Leucocytozoon marchouxi is common in doves and pigeons, but its megalomeronts were reported only in the Mauritian pink pigeon Columba mayeri [186]. It seems that these parasites also develop megalomeronts only in non-adapted avian hosts. Thus, the available data show that the exo-erythrocytic development of haemosporidian parasites is relatively flexible, and it can be modified when the same parasite strain appears in different species of avian host. However, it remains unclear how often such changes occur in wildlife. This issue is related to severity of disease and bird health, and it needs additional investigation. It is essential to expand the application of chromogenic in situ hybridization in research of haemosporidians from simply diagnostic purposes [22, $45,47,94$ ] towards species-level detection of localization of the exo-erythrocytic stages and pathology associated with these stages in various tissues. Sampling of naturally dead birds in zoos, aviaries and wildlife as well as experimental infections of captive birds are most straightforward ways to for such research $[20-25,29,94]$.

\section{Conclusion}

The exo-erythrocytic development of avian haemosporidian parasites requires much additional research. Importantly, the tissue merogony of some avian haemosporidian species and their strains is not as stable as was formerly believed, and it might differ significantly in different avian host species. Understanding the mechanisms of this phenomenon is an important question for future research. Additionally, the use of molecular diagnostic tools and histological methods in parallel have allowed recognition of the existence of underestimated manifestation of haemosporidian infections, which cause diseases and even mortality in birds due to damage of organs by tissue stages. In the latter case, the parasites initiate the exo-erythrocytic development, but cannot complete it in 'wrong' hosts, resulting in the abortive merogony. A problem of the abortive haemosporidian development is related to health both in bird and blood-sucking insects, but remains largely unexplored [22, 27, 30, 229]. This study calls for research on the exo-erythrocytic development, which might broadly inform strategies to mitigate wildlife haemosporidioses due to identifying patterns of occurrence, pathology and mechanisms of abortion in still neglected agents of avian infection. A methodology combining the traditional histological techniques with molecular diagnostic tools is essential to speed research in this field of avian malariology. The prominent knowledge gained due to research by former generations of parasitologists provides a good starting point for addressing mechanisms of exo-erythrocytic development in haemosporidians.

\section{Authors' contributions}

GV collected published articles and collection material, analysed the literature data and wrote the manuscript; GV and TAl analysed preparations of the exo-erythrocytic stages; TAl prepared plates of images. Both authors read and approved the final manuscript.

\section{Acknowledgements}

This article benefited from comments made by Richard W. Ashford. We thank R. Adlard, E. Hoberg and A. Warren for assistance in collecting preparations of tissue stages of haemosporidian parasites, which were deposited in the International Reference Centre for Avian Haematozoa (the Queensland Museum, Queensland), in the US National Parasite Collection, Beltsville (now available in the National Museum of Natural History, Washington, DC), and Natural History Museum (London), respectively. Carter Atkinson kindly provided preparations of the megalomeronts of H. mansoni. Mikas Ilgūnas is acknowledged for technical assistance.

\section{Competing interests}

The authors declare that they have no competing interests.

Availability of data and materials

All data generated during this study are included in this published article.

\section{Funding}

This study was funded by the Research Council of Lithuania (No. MIP-045/2015).

Received: 26 January 2017 Accepted: 20 February 2017

Published online: 03 March 2017

\section{References}

1. Santiago-Alarcon D, Palinauskas V, Schaefer HM. Diptera vectors of avian Haemosporidian parasites: untangling parasite life cycles and their taxonomy. Biol Rev Camb Philos Soc. 2012;87:928-64.

2. Garnham PCC. Malaria parasites and other Haemosporidia. Oxford: Black-well; 1966.

3. Seed TM, Manwell RD. Plasmodia of birds. In: Kreier JP, editor. Parasitic Protozoa Vol III. Gregarines, Haemogregarines, Coccidia, Plasmodia, and Haemoproteids. New York: Academic Press; 1977. p. 311-57.

4. Valkiūnas G. Avian malaria parasites and other Haemosporidia. Boca Raton: CRC; 2005

5. Atkinson CT, Thomas NJ, Hunter DB. Parasitic diseases of wild birds. Oxford: Wiley-Blackwell; 2008.

6. Telford SR. The hemoparasites of the reptilian. Boca Raton: CRC; 2009.

7. Bray RS. Studies on the exo-erythrocytic cycle in the genus Plasmodium. Mem Lond Sch Hyg Trop Med. 1957;12:1-92.

8. Huff CG. Exoerythrocytic stages of avian and reptilian malarial parasites. Exp Parasitol. 1969;24:383-421.

9. Marzal A. Recent advances in studies on avian malaria parasites. In: Okwa OO, editor. Malaria parasites. InTech: Croatia; 2012. p. 135-58.

10. Frevert U, Späth GF, Yee H. Exoerythrocytic development of Plasmodium gallinaceum in the White Leghorn chicken. Int J Parasitol. 2008;38:655-72.

11. Sherman IW, editor. Malaria: parasite biology, pathogenesis, and protection. Washington: ASM; 1998.

12. Sullivan DJ, Krishna S, editors. Malaria: drugs, disease and post-genomic biology. Berlin: Springer; 2005.

13. Clark NJ, Clegg SM, Lima MR. A review of global diversity in avian haemosporidians (Plasmodium and Haemoproteus: Haemosporida): new insights from molecular data. Int J Parasitol. 2014;44:329-38.

14. Perkins SL. Malaria's many mates: past, present and future of the systematics of the order Haemosporida. J Parasitol. 2014;100:11-25.

15. Outlaw RK, Counterman B, Outlaw DC. Differential patterns of molecular evolution among Haemosporidian parasite groups. Parasitology. 2015;142:612-22.

16. Sehgal RN. Manifold habitat effects on the prevalence and diversity of avian blood parasites. Int J Parasitol Parasites Wildl. 2015:4:421-30. 
17. Bensch S, Canbäck B, DeBarry JD, Johansson T, Hellgren O, Kissinger JC, et al. The Genome of Haemoproteus tartakovskyi and its relationship to human malaria parasites. Genome Biol Evol. 2016;8:1361-73.

18. Dimitrov D, lezhova TA, Zehtindjiev P, Bobeva A, llieva M, Kirilova M, et al. Molecular characterisation of three avian haemoproteids (Haemosporida, Haemoproteidae), with the description of Haemoproteus (Parahaemoproteus) palloris n. sp. Syst Parasitol. 2016;93:431-49.

19. Ricklefs RE, Medeiros M, Ellis VA, Svensson-Coelho M, Blake JG, Loiselle BA, et al. Avian migration and the distribution of malaria parasites in New World passerine birds. J Biogeogr. 2016. doi:10.1111/jbi.12928.

20. Cardona CJ, Ihejirika A, McClellan L. Haemoproteus lophortyx infection in Bobwhite Quail. Avian Dis. 2002;46:249-55.

21. Ferrell ST, Snowden K, Marlar AB, Garner M, Lung NP. Fatal hemoprotozoal infections in multiple avian species in a zoological park. J Zoo Wildl Med. 2007;38:309-16.

22. Donovan TA, Schrenzel M, Tucker TA, Pessier AP, Stalis IH. Hepatic hemorrhage, hemocoelom, and sudden death due to Haemoproteus infection in passerine birds: Eleven cases. J Vet Diagn Invest. 2008;20:304-13.

23. Olias P, Wegelin M, Zenker W, Freter S, Gruber AD, Klopfleisch R. Avian malaria deaths in parrots, Europe. Emerg Infect Dis. 2011;17:950-2.

24. Pacheco MA, Escalante AA, Garner MM, Bradley GA, Aguilar RF. Haemosporidian infection in captive masked bobwhite quail (Colinus virginianus ridgwayi), an endangered subspecies of the northern bobwhite quail. Vet Parasitol. 2011;182:113-20.

25. Cannell BL, Krasnec KV, Campbell K, Jones HI, Miller RD, Stephens N. The pathology and pathogenicity of a novel Haemoproteus spp. infection in wild Little Penguins (Eudyptula minor). Vet Parasitol. 2013;197:74-84.

26. Palinauskas V, lezhova TA, Križanauskienè A, Markovets MY, Bensch S, Valkiūnas G. Molecular characterization and distribution of Haemoproteus minutus (Haemosporida, Haemoproteidae): a pathogenic avian parasite. Parasitol Int. 2013;62:358-63.

27. Valkiūnas $G$, Kazlauskienè R, Bernotienè R, Palinauskas V, lezhova TA. Abortive long-lasting sporogony of two Haemoproteus species (Haemosporida, Haemoproteidae) in the mosquito Ochlerotatus cantans, with perspectives on haemosporidian vector research. Parasitol Res. 2013;112:2159-69.

28. Valkiūnas $G$, Kazlauskienè R, Bernotienè R, Bukauskaite $D$, Palinauskas V, lezhova TA. Haemoproteus infections (Haemosporida, Haemoproteidae) kill bird-biting mosquitoes. Parasitol Res. 2014;113:1011-8.

29. Valkiūnas $G$, Palinauskas V, llgūnas M, Bukauskaite D, Dimitrov D, Bernotienè R, et al. Molecular characterization of five widespread avian haemosporidian parasites (Haemosporida), with perspectives on the PCR-based detection of haemosporidians in wildlife. Parasitol Res. 2014;113:2251-63.

30. Valkiūnas G. Haemoproteus species. In: Mehlhorn H, editor. Encyclopedia of parasitology. Berlin: Springer; 2015. p. 1-9.

31. Farmer JN. Gizzard lesions associated with Haemoproteus sacharovi infections of pigeons. Proc lowa Acad Sci. 1964;71:537-42.

32. Levine ND, Beamer PD, Simon J. A disease of chickens associated with Arthrocystis galli n. g, n. sp, an organism of uncertain taxonomic position. H D Srivastava Commen; 1970. p. 429-34.

33. Borst GHA, Zwart P. An aberrant form of Leucocytozoon infection in two quaker parakeets (Myiopsitta monachus Boddaert, 1783). Z Parasitenkd. 1972:40:131-8.

34. Smith GA. Aberrant Leucocytozoon infection in parakeets. Vet Rec. 1972;91:106.

35. Walker D, Garnham PCC. Aberrant Leucocytozoon infection in parakeets. Vet Rec. 1972;91:70-2.

36. Commichau C, Jonas D. Eine durch Leukozytozoon simondi verursachte Erkrankung bei Entenküken unter besonderer Berücksichtigung des histologischen Nachweises. Zbl Vet Med B. 1977;24:662-7.

37. Opitz HM, Jakob HJ, Wiensenhuetter E, Vasandradevi V. A myopathy associated with protozoan schizonts in chickens in commercial farms in peninsular Malaysia. Avian Pathol. 1982;11:527-34.

38. Gardiner $\mathrm{CH}$, Jenkins HJ, Mahoney KS. Myositis and death in bobwhites, Colinus virginianus (L.), due to hemorrhagic cysts of a haemosporozoan of undetermined taxonomic status. J Wildl Dis. 1984;20:308-18.

39. Panigrahy B, Harmon BG, Grumbles LC. Hemorrhagic disease in canaries (Serinus canarius). Avian Dis. 1984;28:536-41.

40. Gardiner CH, Fayer R, Dubey JP. Apicomplexa: Haemoproteus and Haemosporozoa of undetermined taxonomic status. In: An atlas of protozoan parasites in animal tissues. 2nd ed. Washington, DC: Armed Forces Institute of Pathology, American Registry of Pathology; 1988. p. $75-6$.

41. Earlé RA, Bastianello SS, Bennett GF, Krecek RC. Histopathology and morphology of the tissue stages of Haemoproteus columbae causing mortality in Columbiformes. Avian Pathol. 1993;22:67-80.

42. Macwhirter P. Section 7, comparative medicine and management. Chapter 43 Passeriformes. In: Ritchie BW, Harrison GJ, Harrison LR, editors. Avian medicine: principles and application. Lake Worth: Wingers Publishing; 1994. p. 1192-3.

43. Lederer R, Adlard RD, O'Donoghue PJ. Severe pathology associated with protozoal schizonts in two pied currawongs (Strepera graculina) from Queensland. Vet Rec. 2002;150:520-2.

44. Bennett GF, Peirce MA, Ashford RW. Avian haematozoa: mortality and pathogenicity. J Nat Hist. 1993;27:993-1001.

45. Dinhopl N, Nedorost N, Mostegl MM, Weissenbacher-Lang C, Weissenböck H. In situ hybridization and sequence analysis reveal an association of Plasmodium spp. with mortalities in wild passerine birds in Austria. Parasitol Res. 2015;114:1455-62.

46. Mendes L, Pardal S, Morais J, Antunes S, Ramos JA, Peréz-Tris J, Piersma T. Hidden haemosporidian infections in Ruffs (Philomachus pugnax) staging in Northwest Europe en route from Africa to Arctic Europe. Parasitol Res. 2013;112:2037-43.

47. Dinhopl N, Mostegl MM, Richter B, Nedorost N, Maderner A, Fragner K, Weissenböck H. Application of in situ hybridization for the detection and identification of avian malaria parasites in paraffin wax-embedded tissues from captive penguins. Avian Pathol. 2011;40:315-20.

48. Schoener ER, Banda M, Howe L, Castro IC, Alley MR. Avian malaria in New Zealand. NZ Vet J. 2014;62:189-98.

49. Herman CM, Greiner EC, Bennett GF, Laird M. Bibliography of the avian blood-inhabiting Protozoa. St. John's: MUN; 1976.

50. Bennett GF, Kučera J, Woodworth-Lynas C, Whiteway M. Bibliography of the avian blood-inhabiting Protozoa. Mem Univ of Nfld Occ Pap Biol. 1981;4(Suppl 1):1-33.

51. Bishop MA, Bennett GF. Host-parasite catalogue of the avian haematozoa: supplement 1, and Bibliography of the avian blood-inhabiting haematozoa. Mem Univ Nfld Occ Pap Biol. 1992;15(Suppl 2):1-244.

52. Hewitt R. Bird malaria. Baltimore: Jonhs Hopkins Press; 1940.

53. Garnham PCC. Malaria in its various vertebrate hosts. In: Kreier JP, editor. Malaria Part 1. Epidemiology, chemotherapy, morphology and metabolism. New York: Academic Press; 1980. p. 95-144.

54. Huff CG. Observations on the preerythrocytic stages of Plasmodium relictum, Plasmodium cathemerium and Plasmodium gallinaceum in various birds. J Infect Dis. 1951:88:17-26.

55. Huff CG. Organ and tissue distribution of the exoerythrocytic stages of various avian malarial parasites. Exp Parasitol. 1957:6:143-62.

56. Raffaele G. Un ceppo italiano di Plasmodium elongatum. Riv Malar. 1934:13:3-8.

57. James SP, Tate P. New knowledge of the life-cycle of malaria parasites. Nature. 1937;139:545.

58. James SP, Tate P. Exoerythrocytic schizogony in Plasmodium gallinaceum Brumpt, 1935. Parasitology. 1938;30:128-9.

59. Kikuth W, Mudrow L. Die endothelialen Stadien der Malariaparasiten in experiment und theorie. Zentbl Bakt Parasit K. 1938;142:113-33.

60. Vanstreels RE, da Silva-Filho RP, Kolesnikovas CK, Bhering RC, Ruoppolo $\checkmark$, Epiphanio $S$, et al. Epidemiology and pathology of avian malaria in penguins undergoing rehabilitation in Brazil. Vet Res. 2015;46:30.

61. Corradetti A. Relapses and immunological course in Plasmodium infections. Parassitologia. 1959;1:91-6.

62. Coulston F, Cantrell W, Huff CG. The distribution and localization of sporozoites and pre-erythrocytic stages in infections with Plasmodium gallinaceum. J Infect Dis. 1945;76:226-38.

63. McGhee RB. Pre-erythrocytic development of Plasmodium gallinaceum in avian embryos. J Infect Dis. 1949;84:105-10.

64. Corradetti A, Verolini F, Neri I. Plasmodium (Haemamoeba) giovannolain. sp. parassita di Turdus merula. Parassitologia. 1963;5:11-8.

65. Corradetti A, Verolini F, Neri I. Studi sull'infezione da Plasmodium (Haemamoeba) giovannolai nel canarino. Parassitologia. 1963;5:73-85.

66. Garnham PCC, Duggan AJ. Catalogue of the Garnham collection of malaria parasites and other Haemosporidia. London: The Wellcome Trust; 1986. 
67. Gabaldon A, Ulloa G. Las formas exoeritrocíticas de Plasmodium (Haemamoeba) lutzi Lucena, 1939 y presencia de esta especie en Venezuela. Bol Dir Malariol San Amb. 1976;16:299-312.

68. Becker ER. Some unfinished investigations of malaria in pigeons. $J$ Protozool. 1961;8:1-7.

69. Corradetti A, Neri I, Scanga M. Segnalazione in Italia di Plasmodium praecox var. matutinum in Turdus iliacus, e separazione di questo plasmodio da Plasmodium praecox come specie distinta: Plasmodium matutinum Huff, 1937. Parassitologia. 1960;2:333-43.

70. Demina NA. Contribution à l'étude de l'influence du régime nycthéméral de l'hote sur l'évolution de la multiplication de Plasmodium relictum. Riv Malariol. 1959;38:27-44.

71. Huff CG. A new variety of Plasmodium relictum from the robin. J Parasitol. 1937;23:400-4.

72. Manwell RD. Life-cycle of Plasmodium relictum var. matutinum. Am J Trop Med. 1940;20:859-66.

73. Corradetti A, Garnham PCC, Neri L, Scanga M, Cavallini C. A redescription of Plasmodium (Haemamoeba) relictum (Grassi and Feletti, 1891). Parassitologia. 1970;12:1-10.

74. Coulson F, Huff CG. The morphology of cryptozoites and metacryptozoites of $P$. relictum and the relationships of these stages to parasitaemia in canaries and pigeons. J Infect Dis. 1947:80:209-17.

75. Raffaele G. Presumibili forme iniziale di evoluzione di P. relictum. Riv Malar. 1936:15:318-24.

76. Reichenow E, Mudrow L. Der Entwicklungsgang von P. praecox in Vogelkörper. Deutsche Tropenmedizinische Zeitschrift. 1943;46:28-299.

77. Gabaldon A, Ulloa G. Plasmodium (Haemamoeba) tejerai sp. n. del pavo domésstico (Meleagris gallopavo) de Venezuela. Bol Dir Malariol San Amb. 1977:17:255-73.

78. Silveira P, Belo NO, Lacorte GA, Kolesnikovas CKM, Vanstreels RET, Steindel M, Catão-Dias JL, Valkiūnas G, Braga TM. Parasitological and new molecular-phylogenetic characterization of the malaria parasite Plasmodium tejerai in South American penguins. Parasitol Int. 2013;62:165-71.

79. Vanstreels RE, Kolesnikovas CK, Sandri S, Silveira P, Belo NO, Ferreira Junior FC, et al. Outbreak of avian malaria associated to multiple species of Plasmodium in magellanic penguins undergoing rehabilitation in southern Brazil. PLoS ONE. 2014;9:e94994.

80. Corradetti A, Adames A, Neri L, di Giorgi R, Cavallini C. An Italian strain of Plasmodium (Giovannolaia) circumflexum. In: Proceedings. 1st International Congress for Parasitolology. Rome; 1964. p. 238-9.

81. Coulston F, Manwell RD. Single parasite infections and exoerythrocytic schizogony in Plasmodium circumflexum. Am J Hyg. 1941;34:119-25.

82. Huchzermeyer FW, van der Vyver FH. Isolation of Plasmodium circumflexum from wild guineafowl (Numida meleagris) and the experimental infection in domestic poultry. Avian Pathol. 1991;20:213-23.

83. Manwell RD, Goldstein F. Life history and immunity studies of the avian malaria parasite, Plasmodium circumflexum. Proc Soc Exp Biol Med. 1938:39:426-8.

84. Paraense WL. Observaēões sōbre uma amostra brasileira do Plasmodium circumflexum. Mem Inst Oswaldo Cruz. 1952;50:211-41.

85. Huchzermeyer FW. A host-parasite list of the haematozoa of domestic poultry in sub-Saharan Africa and the isolation of Plasmodium durae Herman from turkeys and francolins in South Africa. Onderstepoort J Vet Res. 1993;60:15-21.

86. Huchzermeyer FW. Pathogenicity and chemotherapy of Plasmodium durae in experimentally infected domestic turkeys. Onderstepoort J Vet Res. 1993;60:103-10.

87. Laird M. Plasmodium durae Herman from the introduced common peafowl in Northern Nigeria. J Protozool. 1978;25:21-4.

88. Purchase HS. Turkey malaria. Parasitology. 1942;34:278-83.

89. Simpson ML. Exoerythrocytic stages of P. durae. J Parasitol. 1944;30:177-8.

90. Huff CG, Marchbank DF, Saroff AH, Scrimshaw PW, Shiroishi T. Experimental infections with Plasmodium fallax Schwetz isolated from the Uganda tufted guinea fowl Numida meleagris major Hartlaub. J Natl Malar Soc. 1950;9:307-19.

91. Huff CG, Weathersby AB, Pipkin AC, Algire GH. The growth of exoerythrocytic stages of avian malaria within diffusion chambers in different hosts. Exp Parasitol. 1960;9:98-104.
92. Garnham PCC. A new malaria parasite of pigeons and ducks from Venezuela. Protistologica. 1977;13:113-25.

93. Guindy E, Hoogstraal H, Mohammed AHH. Plasmodium garnhami sp. nov. from the Egyptian hoopoe (Upupa epops major Brehm). Trans R Soc Trop Med Hyg. 1965;59:280-4.

94. Ilgūnas M, Bukauskaitè D, Palinauskas V, lezhova TA, Dinhopl N, Nedorost N, et al. Mortality and pathology in birds due to Plasmodium (Giovannolaia) homocircumflexum infection, with emphasis on the exoerythrocytic development of avian malaria parasites. Malar J. 2016;15:256.

95. Huff CG, Coulston F, Laird RL, Porter RJ. Pre-erythrocytic development of Plasmodium lophurae in various hosts. J Infect Dis. 1947;81:7-13.

96. Manresa M. The occurrence of phanerozoites of Plasmodium lophurae in blood inoculated turkeys. J Parasitol. 1953;39:452-5.

97. Tonkin IM, Hawking F. Growth of Protozoa in tissue culture. IV. Plasmodium lophurae, exoerythrocytic forms, in vivo and in vitro. Trans R Soc Trop Med Hyg. 1947;41:407-17.

98. Manwell RD. Plasmodium octamerium n. Sp., an avian malaria parasite from the pintail whydah bird Vidua macroura. J Protozool. 1968;15:680-5.

99. Muniz J, Soares R. Nota sōbre um parasita do genero Plasmodium encontrado no Ramphastos toco Müller, 1776, "Tugano-Aēu", e diferente do Plasmodium huffi: Plasmodium pinottii n. sp. Rev Bras Malariol. 1954:6:611-7.

100. Ayala SC, Varela CE. Malaria in Chordeiles minor (Aves: Caprimulgidae), an intercontinental migrant. Rev Inst Med Trop Sao Paulo. 1975;17:253-6.

101. Corradetti A, Scanga M. Notes on Plasmodium (Giovannolaia) polare and its transmission with Culiseta longiareolata. Parassitologia. 1965;7:61-4.

102. Greiner EC, Black DJ, Iverson WO. Plasmodium in a bald eagle (Haliaeetus leucocephalus) in Florida. J Wildl Dis. 1981;17:555-8.

103. Telford SR, Nesbitt SA, Spalding MG, Forrester DJ. A species of Plasmodium from sandhill cranes in Florida.J Parasitol. 1994:80:497-9.

104. Gabaldon A, Ulloa G. A new species of the subgenus Novyella (Haemosporina, Plasmodiidae) from Aramides cajanea (Gruiformes, Rallidae). In: Canning EU, editor. Parasitological topics. A presentation volume to P.C.C. Garnham, F.R.S. on the occasion of his 80th birthday. 1981. p. $100-5$.

105. de Jong AC. Plasmodium dissanaikei n. sp. a new avian malaria parasite from the rose-ringed parakeet of Ceylon, Psittacula krameri manillensis. Ceylon J Med Sci. 1971;20:41-5.

106. Manwell RD. Exoerythrocytic schizogony in Plasmodium hexamerium. Am J Hyg. 1951;53:244-8.

107. Huff CG. Exoerythrocytic stages of Plasmodium nucleophilum. J Parasitol. 1956:42:612.

108. Manwell RD, Sessler GJ. Malaria parasites of toucans. J Protozool. $1971 ; 18: 570-4$

109. Manwell RD, Sessler GJ. Plasmodium paranucleophilum n. sp. from a South American tanager. J Protozool. 1971;18:629-32.

110. Corradetti A, Scanga M. Plasmodium (Novyella) vaughani subsp. merulae, n. subsp., parassita di Turdus merula, con descrizione del ciclo pre-eritrocitico. Parassitologia. 1972;14:85-93.

111. Nelson P. Exo-erythrocytic stages of a Ceylon strain of Plasmodium vaughani in pigeons. Trans R Soc Trop Med Hyg. 1966;60:424.

112. Barretto MP. Malária Aviária: III. Sobre o encontro de formas exoeritocíticas do 'Plasmodium juxtanucreare' Versiani e Gomas, 1941. O Hospital; 1943. p. 643-5.

113. Dhanapala SB. The occurrence of Plasmodium juxtanucleare Versiani and Gomes 1941 in domestic fowls in Ceylon. Riv Malar. 1962;41:39-46.

114. Paraense WG. Observações preliminaries sobre o ciclo exoeritroocitário do Plasmodium juxtanucleare Versiani e Gomes 1941. Mems Inst Oswaldo Cruz. 1947:45:813-24.

115. Corradetti A, Neri I, Scanga M, Cavallini C. I cicli pre-eritrocitico e sporogonico di Plasmodium (Huffia) elongatum. Parassitologia. 1968;10:133-43.

116. Garnham PCC. Patterns of exoerythrocytic schizogony. Br Med Bull. 1951;8:10-5.

117. Palinauskas $V$, Žiegytè $R$, lezhova $T A$, Ilgūnas $M$, Bernotienè $R$, Valkiūnas G. Description, molecular characterisation, diagnostics and life cycle of Plasmodium elongatum (lineage pERIRUB01), the virulent avian malaria parasite. Int J Parasitol. 2016;46:697-707. 
118. Raffaele G. Un ceppo italiano di Plasmodium elongatum. Riv Malariol. 1934;13:332-7.

119. Forrester DJ, Humphrey PP. Susceptibility of the knot (Calidris canutus) to Plasmodium hermani. J Parasitol. 1981;67:747-8.

120. Forrester DJ, Nayar JK, Young MD. Natural infection of Plasmodium hermani in the northern bobwhite, Colinus virginianus, in Florida. J Parasitol. 1987;73:865-6.

121. Nayar JK, Young MD, Forrester DJ. Experimental transmission by mosquitoes of Plasmodium hermani between domestic turkeys and pen-reared bobwhites. J Parasitol. 1982;68:874-6.

122. Telford SR, Forrester DJ. Plasmodium (Huffia) hermani sp. n. from wild turkeys (Meleagris gallopavo) in Florida. J Protozool. 1975;22:324-8.

123. Huff CG. Observations on Plasmodium huffi Muniz, Soares et Batista. Am J Trop Med Hyg. 1953;2:620-3.

124. Muniz J, Soares R, Batista S. Sōbre uma espécie de Plasmodium parasita do Ramphastos toco Müller, 1776. Plasmodium huffi n. sp. Rev Bras Malariol. 1951;3:339-44.

125. Grilo ML, Vanstreels RET, Wallace R, García-Párraga D, Braga EM, Chitty J, et al. Malaria in penguins-current perceptions. Avian Pathol. 2016:45:393-407.

126. Howe L, Castro IC, Schoener ER, Hunter S, Barraclough RK, Alley MR. Malaria parasites (Plasmodium spp.) infecting introduced, native and endemic New Zealand birds. Parasitol Res. 2012;110:913-23.

127. Palinauskas V, Žiegytè R, llgūnas $M$, lezhova TA, Bernotienè R, Bolshakov C, et al. Description of the first cryptic avian malaria parasite, Plasmodium homocircumflexum $\mathrm{n}$. sp. with experimental data on its virulence and development in avian hosts and mosquitoes. Int J Parasitol. 2015:45:51-62.

128. Permin A, Juhl J. The development of Plasmodium gallinaceum infections in chickens following single infections with three different dose levels. Vet Parasitol. 2002;105:1-10.

129. Fleischman RW, Squire RA, Sladen WJL, Melby EC. Malaria (Plasmodium elongatum) in captive African penguins (Spheniscus demersus). J Am Vet Med Assoc. 1968;153:928-35.

130. Porter RJ. The tissue distribution of exoerythrocytic schizonts in sporozoites-induces infections with Plasmodium cathemerium. J Infect Dis. 1942;71:1-17.

131. Hegner R, Wolfson F. Association of Plasmodium and Toxoplasma-like parasites in birds. Am J Hyg. 1938;28:437-54.

132. Mohammed AHH. Systematic and experimental studies on protozoan blood parasites of Egyptian birds. Cairo: Cairo University Press; 1958.

133. Valkiūnas $G$, Ilgūnas $M$, Bukauskaitė $D$, Žiegytè R, Bernotienè R, Jusys $\checkmark$, et al. Plasmodium delichoni $\mathrm{n}$. sp.: description, molecular characterisation and remarks on the exoerythrocytic merogony, persistence, vectors and transmission. Parasitol Res. 2016;115:2625-36.

134. Valkiūnas G, lezhova TA, Loiseau C, Smith TB, Sehgal RNM. New malaria parasites of the subgenus Novyella in African rainforest birds, with remarks on their high prevalence, classification and diagnostics. Parasitol Res. 2009;104:1061-77.

135. Mantilla JS, González AD, Valkiūnas G, Moncada LI, Matta NE. Description and molecular characterization of Plasmodium (Novyella) unalis sp. nov. from the Great Thrush (Turdus fuscater) in highland of Colombia. Parasitol Res. 2013;112:4193-204.

136. Holding PA, Snow RW. Impact of Plasmodium falciparum malaria on performance and learning: review of the evidence. Am J Trop Med Hyg. 2001;64(Suppl 1-2):68-75.

137. Adams Y, Kuhnrae P, Higgins MK, Ghumra A, Rowe JA. Rosetting Plasmodium falciparum-infected erythrocytes bind to human brain microvascular endothelial cells in vitro, demonstrating a dual adhesion phenotype mediated by distinct $P$. falciparum erythrocyte membrane protein 1 domains. Infect Immun. 2014;82:949-59.

138. Lainson R, Landau I, Shaw JJ. On a new family of non-pigmented parasites in the blood of reptiles: Garniidae fam. nov., (Coccidiida: Haemosporidiidea). Some species of the new genus Garnia. Int J Parasitol. 1971;1:241-50.

139. Lainson R. Atlas of protozoan parasites of the Amazonian fauna of Brazil. Vol. 1. Haemosporida of reptiles, vol. 1. Ananindeua: Instituto Evandro Chagas; 2012.

140. Amoudi MA, Alyousif MS, Saifi MA, Alanazi AD. A new species of plasmodiidae (Coccidia: Hemosporidia) from the blood of the skink
Scincus hemprichii (Scincidae: Reptilia) in Saudi Arabia. Saudi J Biol Sci. 2015;22:312-6.

141. Perkins SL. Species concepts and malaria parasites: detecting a cryptic species of Plasmodium. Proc Biol Sci. 2000;267:2345-50.

142. Gabaldon A, Ulloa G, Zerpa N. Fallisia (Plasmodioides) neotropicalis subgen. nov. sp. nov. from Venezuela. Parasitology. 1985;90:217-25.

143. Outlaw DC, Ricklefs RE. Species limits in avian malaria parasites (Haemosporida): how to move forward in the molecular era. Parasitology. 2014;141:1223-32.

144. Levin II, Valkiūnas G, lezhova TA, O'Brien SL, Parker PG. Novel Haemoproteus species (Haemosporida: Haemoproteidae) from the swallow-tailed gull (Lariidae), with remarks on the host range of hippoboscid-transmitted avian hemoproteids. J Parasitol. 2012;98:847-54.

145. lezhova T. Comparative morphology of haemoproteids (Haemosporidia, Haemoproteidae) of the Palearctic birds (in Russian). Ph.D. Thesis. Vilnius: Institute of Ecology; 1994.

146. Peirce MA. Haemoproteus balearicae sp. nov., from crowned cranes, Balearica pavonina pavonina and B. pavonina gibbericeps. Bull Epizoot Dis Afr. 1973;21:467-75.

147. Khan RA, Fallis AM. Endogenous stages of Parahaemoproteus fringillae (Labbé, 1894) and Leucocytozoon fringillinarum Woodcock, 1910. Can J Zool. 1969:47:37-9.

148. Peirce MA, Lederer R, Adlard RD, O'Donoghue PJ. Pathology associated with endogenous development of haematozoa in birds from southeast Queensland. Avian Pathol. 2004;33:445-50.

149. Miltgen F, Landau I, Ratanaworabhan N, Yenbutra S. Parahaemoproteus desseri n. sp.; Gamétogonie et schizogonie chez l'hôte naturel: Psittacula roseata de Thailande, et sporogonie expérimentale chez Culicoides nubeculosus. Ann Parasitol Hum Comp. 1981:56:123-30.

150. Atkinson CT, Greiner EC, Forrester DJ. Pre-erythrocytic development and associated host responses to Haemoproteus meleagridis (Haemosporina: Haemoproteidae) in experimentally infected domestic turkeys. J Protozool. 1986;33:375-81.

151. Atkinson CT, Forrester DJ, Greiner EC. Pathogenicity of Haemoproteus meleagridis (Haemosporina: Haemoproteidae) in experimentally infected domestic turkeys. J Protozool. 1988;74:228-39.

152. Sibley LD, Werner JK. Susceptibility of pekin and muscovy ducks to Haemoproteus nettionis. J Wild Dis. 1984;20:108-13.

153. Anschütz G. Ueber den Entwickelungsgang des "Haemoproteus orizivorae" nov. spec. Zentralbl Bakteriol Parasitenkd Infektionskr Hyg I Abt Orig. 1909;51:654-9.

154. Burtikashvili LP. New species of blood parasite, Haemoproteus zasukhini sp. nov. (Sporozoa, Haemoproteidae) from the house sparrow (Passer domesticus L.) (in Russian). Soobsh Akad Nauk Gruz SSR. 1973;72:697-700.

155. Burtikashvili LP. Blood parasites of wild birds in Georgia. Tbilisi: Metsniereba; 1978 (In Russian).

156. Peirce MA. Haemoproteid parasites of Passer spp. Parasitology. 1976;73:407-15.

157. Wenyon CM. Protozoology: a manual for medical men, veterinarians and zoologists, etc. London: Bailliére Tindal \& Cox; 1926.

158. Garvin MC, Homer BL, Greiner EC. Pathogenicity of Haemoproteus danilewskyi, Kruse, 1890, in Blue Jays (Cyanocitta cristata). J Wildl Dis. 2003;39:161-9.

159. Ahmed FE, Mohammed AHH. Schizogony in Haemoproteus columbae Kruse. J Protozool. 1977;24:389-93.

160. Acton HW, Knowles R. Studies on the halteridium parasite of the pigeon, Haemoproteus columbae Celli and San Felice. Indian J Med Res. 1914:1:663-90.

161. Aragão HB. Über den Entwicklungsgang and die Übertragung von Haemoproteus columbae. Arch Protistenkd. 1908;12:154-67.

162. Huff CG. Schizogony and gametocyte development in Leucocytozoon simondi, and comparison with Plasmodium and Haemoproteus. I Infect Dis. 1942;71:18-32.

163. Linxian H, Yuguang L, Hongping J. On sporogony and schizogony of Haemoproteus columbae of pigeon. Acta Zool Sinica. 1989;35:306-12.

164. Mohammed AHH. Studies on the schizogony of Haemoproteus columbae Kruse, 1890. Proc Egypt Acad Sci. 1967;19:37-46.

165. Baker JR. Haemoproteus palumbis sp. nov. (Sporozoa, Haemosporina) of the English Wood-Pigeon Columba p. palumbus. J Protozool. 1966;13:515-9. 
166. Desser SS, Bennett GF. The genera Leucocytozoon, Haemoproteus and Hepatocystis. In: Kreier JP, Baker JR, editors. Parasitic protozoa. 2nd ed. Cambridge: Academic Press; 1993. p. 273-307.

167. Mutlow A, Forbes N. Haemoproteus in raptors: pathogenicity, treatment and control. Wallbridge: Landsdown Veterinary Surgeons; 1999.

168. Paperna I, Gil H. Schizogonic stages of Haemoproteus from Wenyon's Baghdad sparrows are also found in Passer domesticus biblicus in Israel. Parasitol Res. 2003;91:486-90.

169. Fowler NG, Forbes GB. Aberrant Leucocytozoon infection in parakeets. Vet Rec. 1972;91:345-7.

170. Markus MB. Leucocytozoon infection in parakeets. Vet Res. 1972;91:323

171. Garnham PCC. Epizootics of Leucocytozoon infections in parakeets in England. In: Progress in parasitology: abstracts of papers read at the 4-th International Congress; 1973.

172. Simpson VR. Leucocytozoon-like infections in parakeets, budgeries and a common buzzard. Vet Rec. 1991;13:30-2.

173. Forrester DJ, Greiner EC. Leucocytozoonosis. In: Atkinson CT, Thomas NJ, Hunter DB, editors. Parasitic diseases of wild birds. Oxford: WileyBlackwell; 2008. p. 54-107

174. Peirce MA, Adlard RD, Lederer R. A new species of Leucocytozoon Berestneff, 1904 (Apicomplexa: Leucocytozoidae) from the avian family Artamidae. Syst Parasitol. 2005;60:151-4

175. Clark GW. Schizogony and gametocyte development of Leucocytozoon berestneffi in the yellow-billed magpie Pica nuttalli. J Protozool. 1965;12:584-9.

176. Khan RA, Fallis AM. Speciation, transmission, and schizogony of Leucocytozoon in corvid birds. Can J Zool. 1971;49:1363-7.

177. Khan RA. Development of Leucocytozoon ziemanni (Laveran). J Parasitol. 1975:61:449-57.

178. Wong TC, Desser SS. An ultrastructural study of the schizogonic development of Leucocytozoon dubreuili in the liver of the American robin, Turdus migratorius. Protistologica. 1981;17:11-27.

179. Khan RA, Fallis AM. Life cycles of Leucocytozoon dubreuili Mathis and Léger, 1911 and L. fringillinarum Woodcock, 1910 (Haemosporidia: Leucocytozoidae). J Protozool. 1970;17:642-58.

180. Wong TC, Desser SS. Ultrastructural observations on renal schizogony of Leucocytozoon dubreuili in the American robin. J Protozool. 1978;25:302-14.

181. Borg K. On Leucocytozoon is Swedish capercaillie, black grouse and hazel grouse. Lund: Lund Publisher; 1953.

182. Clarke CHD. Organisms of a malarial type in ruffed grouse, with a description of the schizogony of Leucocytozoon bonasae. J Wildl Manag. 1938;2:146-50.

183. Newman MW. Large schizonts of Leucocytozoon from the kidney of the ruffed grouse (Bonasa umbellus). Can J Zool. 1970;48:879-80.

184. Hong L, Chen X, Lin Y. The sporogony and schizogony of Leucocytozoon sabrazesi from chicken in China. Bull Soc Fr Parasitol. 1990;8(Suppl. 1):321.

185. de Jong AC. Leucocytozoon neavei in francolins, Francolinus (=Pternistis) leucoscepus. Ceylon Vet J. 1971;19:92-5.

186. Peirce MA, Cheke AS, Cheke RA. A survey of blood parasites of birds in the Mascarene Islands, Indian Ocean with descriptions of two new species and taxonomic discussion. Ibis. 1977;119:451-61.

187. Adlard RD, Peirce MA, Lederer R. New species of Leucocytozoon from the avian families Otidae, Podargidae and Threskiornithidae. J Nat Hist. 2002;36:1261-7

188. Baker JR. Transmission of Leucocytozoon sakharoffi in England by Simulium angustitarse. Parasitology. 1970;60:417-23.

189. Baker JR. Sporogony and schizogony of Leucocytozoon sakharoffi in England. J Protozool. 1971;18(Suppl):40.

190. Baker JR. Protozoan parasites of the blood of British wild birds and mammals. J Zool. 1974;172:169-90.

191. Wingstrand KG. On some haematozoa of Swedish birds with remarks on the schizogony of Leucocytozoon sakharoffi. Kungl Sven Vetenskap sakad Handl. 1947;24:1-31.

192. Wingstrand KG. Further studies on Leucocytozoon sakharoffi. Kungl Sven Vetenskapsakad Handl. 1948;24:1-17.

193. Chernin E. The relapse phenomenon in the Leucocytozoon simondi infection of the domestic duck. Am J Hyg. 1952;56:101-18.

194. Cowan AB. Reactions against the megaloschizonts of Leucocytozoon simondi Mathis and Léger in ducks. J Infect Dis. 1957;100:82-7.
195. Desser SS. Schizogony and gametogony of Leucocytozoon simondi and associated reactions in the avian host. J Protozool. 1967;14:244-54.

196. Desser SS. The fine structure of Leucocytozoon simondi II. Megaloschizogony. Can J Zool. 1970;48:417-21.

197. Desser SS. The fine structure of Leucocytozoon simondi. VI. Hepatic schizogony. Can J Zool. 1973;51:605-9.

198. Desser SS, Fallis AM. The cytological development and encapsulation of megaloschizonts of Leucocytozoon simondi. Can J Zool. 1967;45:1061-5.

199. Desser SS, Fallis AM, Garnham PCC. Relapses in ducks chronically infected with Leucocytozoon simondi and Parahaemoproteus nettionis. Can J Zool. 1968:46:281-5.

200. Desser SS, Stuht J, Fallis AM. Leucocytozoonosis in Canada geese in Upper Michigan. I. Strain differences among geese from different localities. J Wildl Dis. 1978;14:124-31.

201. Desser SS, Ryckman AK. The development and pathogenesis of Leucocytozoon simondi in Canada and domestic geese in Algonquin Park, Ontario. Can J Zool. 1976;54:634-43.

202. Eide A, Fallis AM. Experimental studies of the life cycle of Leucocytozoon simondi in ducks in Norway. J Protozool. 1972;19:414-6.

203. Fallis AM, Davies DM, Vickers MA. Life history of Leucocytozoon simondi Mathis and Léger in natural and experimental infections and blood changes produced in the avian host. Can J Zool. 1951;29:305-28.

204. Newberne JW. Studies on the histopathology of Leucocytozoon simondi infection. Am J Vet Res. 1957:18:191-9.

205. Karstad L. A case of leucocytozoonosis in a wild mallard. Bull Wildl Dis Ass. 1965;1:33-4.

206. Khan RA, Desser SS, Fallis AM. Survival of sporozoites of Leucocytozoon in birds for 11 days. Can J Zool. 1969;47:347-50.

207. O'Roke EC. A malaria-like disease of ducks caused by Leucocytozoon anatis Wickware. Univ Mich Sch Cons Bull. 1934;4:1-44.

208. Yang YJ. In vitro cultivation of exoerythrocytic stages of Leucocytozoon simondi. Can J Zool. 1971;49:561-3.

209. Yang YJ, Desser SS, Fallis AM. Elongate and round gametocytes of Leucocytozoon simondi (Mathis et Léger) in ducks inoculated with megaloschizonts. J Protozool. 1971;18:553-6.

210. Newberne JW. The pathology of Leucocytozoon infection in turkeys with a note on its tissue stages. Am J Vet Res. 1955;16:593-7.

211. Steele EJ, Noblet GP. Schizogonic development of Leucocytozoon smithi. J Protozool. 1992;39:530-6.

212. Richey DJ, Ware RE. Schizonts of Leucocytozoon smithi in artificially infected turkeys. Cornell Vet. 1955;45:642-3.

213. Wehr EE. Studies on leucocytozoonosis of turkeys, with notes on schizogony, transmission, and control of Leucocytozoon smithi. Avian Dis. 1962;6:95-210.

214. Allison FR, Desser SS. Observations on the life cycle of the haemosporidian Leucocytozoon tawaki in the simuliid vector and the New Zealand fiordland crested penguin, Eudyptes pachyrhynchus. In: Short commun. 4th International Congress of Parasitology. Warsaw; 1978.

215. Fallis AM, Bisset SA, Allison FR. Leucocytozoon tawaki n. sp. (Eucoccida: Leucocytozoidae) from the penguin Eudyptes pachyrhynchus, and preliminary observations on its development in Austrosimulium spp. (Diptera: Simuliidae). NZ J Zool. 1976;3:11-6.

216. Akiba K. Leucocytozoonosis of chickens. Nat Inst Anim HIth Q. 1970;10(Suppl):131-47.

217. Akiba K, Kawashima H, Inui S, Ishii S. Studies on Leucocytozoon of chickens in Japan. I. Natural infection of L. caulleryi. Bull Natl Inst Anim HIth. 1958:34:163-80

218. Akiba K, Inui S, Ishitani R. Morphology and distribution of intracellular schizonts in chickens experimentally infected with Akiba caulleryi. Natl Inst Anim Hlth Q. 1971;11:109-21.

219. Chew M. Megaloschizonts of Leucocytozoon in the eyes and sciatic nerves of the domestic fowl. Vet Rec. 1968;83:518-9.

220. Kitaoka S, Morii T, Fujisaki K. Quantitative observation on schizogony of Akiba caulleryi in chickens. Nat Inst Anim HIth Q. 1972;12:151-60.

221. Lee HR, Koo BS, Jeon EO, Han MS, Min KCh, Lee SB, Bae Y, Mo IP. Pathology and molecular characterization of recent Leucocytozoon caulleryi cases in layer flocks. J Biomed Res. 2016;30:517-24.

222. Omar AR. Haemoprotozoan infections of poultry in Malaysia. Kajian Vet. 1968;1:109-24.

223. Morii T. A review of Leucocytozoon caulleryi infection in chickens. J Protozool Res. 1992;2:128-33. 
224. Morii T, Nakamura K, Lee YC, lijima T, Hoji K. Observations on the Taiwanese strain of Leucocytozoon caulleryi (Haemosporina) in chickens. J Protozool. 1986;33:231-4.

225. Morii T, Matsui T, Kobayashi F, lijima T, Fukuda M. Freeze fracture study of the schizonts and merozoites of Leucocytozoon caulleryi. Zbl Bakt Hyg A. 1987;264:527-35.

226. Morii T, Fukuda M. Observations on first-generation schizogony of Leucocytozoon caulleryi in chickens. J Protozool. 1992;39:281-7.

227. Takamatsu H, Fujisaki K, Kitaoka S. Development of Leucocytozoon caulleryi in chick embryos infected by biting of Culicoides arakawae through shell membrane. Natl Inst Anim Health Q. 1978;18:63-8.
228. Desser SS, Baker JR, Lake P. The fine structure of Leucocytozoon simondi. I. Gametogenesis. Can J Zool. 1970;48:331-6.

229. Bukauskaitè D, Bernotienè R, lezhova TA, Valkiūnas G. Mechanisms of mortality in Culicoides biting midges due to Haemoproteus infection. Parasitology. 2016;143:1748-54.

\section{Submit your next manuscript to BioMed Central and we will help you at every step:}

- We accept pre-submission inquiries

- Our selector tool helps you to find the most relevant journal

- We provide round the clock customer support

- Convenient online submission

- Thorough peer review

- Inclusion in PubMed and all major indexing services

- Maximum visibility for your research

Submit your manuscript at

www.biomedcentral com/submit 